Article

\title{
Implementation, Comparison and Application of an Average Simulation Model of a Wind Turbine Driven Doubly Fed Induction Generator
}

\author{
Lidula N. Widanagama Arachchige ${ }^{1, *}$, Athula D. Rajapakse ${ }^{2}$ and Dharshana Muthumuni ${ }^{3}$ \\ 1 Department of Electrical Engineering, University of Moratuwa, Moratuwa 10400, Sri Lanka \\ 2 Department of Electrical and Computer Engineering, University of Manitoba, Winnipeg, MB R3T 5V6, \\ Canada; athula.rajapakse@umanitoba.ca \\ 3 Manitoba HVDC Research Centre, Winnipeg, MB R3P 1A3, Canada; dharshana@hvdc.ca \\ * Correspondence: lidulan@uom.lk; Tel.: +94-011-265-0301
}

Received: 4 October 2017; Accepted: 25 October 2017; Published: 27 October 2017

\begin{abstract}
Wind turbine driven doubly-fed induction generators (DFIGs) are widely used in the wind power industry. With the increasing penetration of wind farms, analysis of their effect on power systems has become a critical requirement. This paper presents the modeling of wind turbine driven DFIGs using the conventional vector controls in a detailed model of a DFIG that represents power electronics (PE) converters with device level models and proposes an average model eliminating the PE converters. The PSCAD/EMTDC ${ }^{\mathrm{TM}}$ (4.6) electromagnetic transient simulation software is used to develop the detailed and the proposing average model of a DFIG. The comparison of the two models reveals that the designed average DFIG model is adequate for simulating and analyzing most of the transient conditions.
\end{abstract}

Keywords: average simulation model; doubly-fed induction generator; DFIG model; electromagnetic transients; wind turbine

\section{Introduction}

With the improvements of wind power generation technology and associated cost reductions, the global installed wind capacity has grown at a rapid rate during the last decade [1]. Cumulative global wind power installed capacity in 1996 was about 6 GW and by 2016 it had grown to 487 GW [2]. A survey has revealed that wind market is still dominated by the doubly-fed induction generator (DFIG) technology [3].

With the increasing penetration of wind turbine-driven DFIGs into distribution and transmission networks, the impact of these on the power systems has become a concern. Many recently published research papers investigate the influence of wind farm integration on control, stability, subsynchronous oscillations, etc. Many of these studies rely on time-domain simulations. For example, a virtual inertia and primary frequency control strategy for a DFIG, which operates in coordination with a diesel generator to participate in the frequency regulation of wind/photovoltaic/diesel microgrid, is proposed in [4]. The proper operation of the methodology is validated through time domain simulations utilizing a detailed model of a DFIG that represents power electronics (PE) converters with device level models. Another study [5], investigates subsynchronous resonance (SSR) resulting from a series-compensated network connected to a DFIG-based wind farm and proposes a SSR mitigation technique. The effectiveness of the proposed method is verified through time-domain simulations which reflect the actual dynamic behaviour during disturbances. Neither of $[4,5]$ present sufficient information on the DFIG models used.

Electromagnetic transient (EMT) simulations are generally used for dynamic simulation of power systems containing power electronics devices. Modelling and simulation of a detailed DFIG model, 
where PE converters are modeled with device level details, in PSCAD/EMTDC is presented in [6]. It describes the simulation models of the machine, wind turbine and PE converter controls in detail, and presents performance of the developed DFIG simulation model when connected to a simple radial power system having a nonlinear load. A discussion on dynamic modeling of DFIG is presented in [7] with a focus on the machine and turbine modeling. The converter control is not properly discussed in [7]. It presents the use of crow-bar protection for the rotor side converter and illustrates the performance of the developed DFIG model under system faults.

Many of the studies cited above need long duration simulations, especially when studying phenomena influenced by mechanical inertia and low frequency oscillations. When the detailed PE converter models are used in the DFIG model, EMT simulations takes considerable computing resources and time. This is cumbersome, if the simulations need to be repeated many times. In order to address this, an average model of a DFIG driven by a wind turbine is presented in [8]. The EMT simulation model of the power systems is developed using the Matlab (4) Simulink-based SimPowerSystems software. The paper discusses the modelling of the wind turbine and its operation in detail, while briefly stating how the average model of the converters developed. A different simplified transient model of a DFIG is used in [9] to study the inertia characteristics of a DFIG wind turbine under transient control. The paper analyzes the impact of DFIG wind turbine on the first-swing stability of synchronous generators using the simplified DFIG model, but its accuracy is not validated.

This paper addresses the general lack of details of modeling wind turbine-driven DFIGs for EMT simulations, and the need for properly validated simplified models for long duration EMT simulations. This paper differs from the previous literature due to following features: the paper focuses more on the basis and details of converter controls, develops both detailed and average models of a DFIG, and extensively validates the developed average DFIG model against the detailed DFIG model. The limitations of the average DFIG model, which represents PE converters using controlled voltage and current sources, are also discussed. Finally, the application of both models in a medium voltage distribution network is demonstrated.

\section{Wind Turbine Driven DFIG Control}

In a DFIG, a wound rotor induction machine is used with the rotor winding being fed through partial-scale (only $25-30 \%$ of the generator capacity) back-to-back converters [3-7]. The stator is directly connected to the grid while the rotor is connected to the grid through power electronic converters. The block diagram of a typical configuration of the wind turbine driven DFIG is shown in Figure 1.

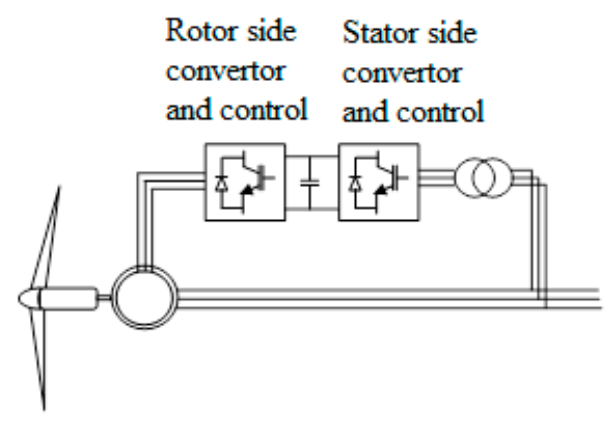

Figure 1. The arrangement of a DFIG driven by a wind turbine.

The detailed model of a wind turbine driven DFIG includes details up to the PE switches in the converters. In the proposed average model, the PE convertors are replaced with controlled voltage and current sources. 


\subsection{Converter Control in the Detailed Model of DFIG}

The stator winding currents of a 3-phase induction machine produce a resultant rotating magnetic flux of constant magnitude and speed in the airgap. Therefore, the machine can be represented as a rotor placed between a 2-pole magnet rotating at the synchronous speed $\omega_{s}$ as illustrated in Figure 2 . With reference to Figure 2, the current carrying rotor conductors lying directly across the resultant stator magnetic flux $\left(\phi_{s}\right)$, experience a force (torque) in accordance with the Fleming's left-hand rule, giving rise to the active power output of the machine. The rotor conductors lying $90^{\circ}$ to the $\mathrm{d}$-axis do not experience a force, and are accountable for the reactive power output of the machine. Therefore, in a DFIG, active power, reactive power and/or speed can be controlled by injecting an appropriate current into the rotor conductors.

This is achieved by using the back-to-back IGBT voltage-source converters with a common DC bus as shown in Figure 1. The rotor side converter controls the power flow between the DC bus and the AC side, while the grid side converter is operated to keep the DC voltage on the capacitor constant [6].

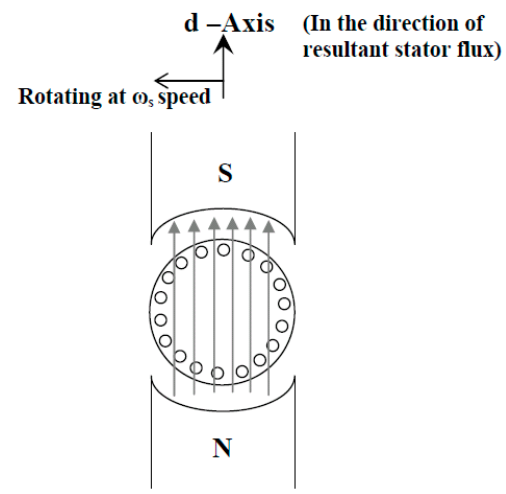

Figure 2. Illustration of stator d-Axis for a DFIG.

\subsubsection{Rotor Side Converter Control}

In analysing the DFIG operation, the rotating resultant flux direction is taken as the d-axis of the stator. The current carrying conductors of the rotor lying directly across the resultant stator magnetic flux $\left(\phi_{s}\right)$ have a magnetic axis perpendicular to $\phi_{s}$. Therefore, the rotor d-axis is perpendicular to the stator d-axis. This implies that the rotor q-axis current $\left(I_{q r}\right)$ influences active power (or speed) and the rotor d-axis current $\left(I_{d r}\right)$ influences reactive power. Therefore, in order to ensure the required power flow, $I_{d r}$ and $I_{q r}$ components of rotor currents are controlled using PI controllers. The corresponding phase current references $i_{r a, r e f}, i_{r b, r e f}$, and $i_{r c, r e f}$ are generated at the voltage source converter to force these currents into the rotor. This is achieved using a current referenced PWM technique.

Therefore, initial step is to obtain the instantaneous position of the rotating flux vector in the space. The phasor representation of the rotor and stator axes of a DFIG is given in Figure 3, and the per phase equivalent circuit of a wound rotor induction generator is shown in Figure 4. Figure 4 shows that the stator instantaneous voltage after subtracting the resistive drop, gives the derivative of the stator flux linkage per phase as given by Equations (1):

$$
\begin{aligned}
& u_{A s}=r_{A s} i_{A s}+\frac{\mathrm{d} \lambda_{A s}}{\mathrm{~d} t} \\
& u_{B s}=r_{B s} i_{B s}+\frac{\mathrm{d} \lambda_{B s}}{\mathrm{~d} t} \\
& u_{C s}=r_{C s} i_{C s}+\frac{\mathrm{d} \lambda_{C s}}{\mathrm{~d} t}
\end{aligned}
$$




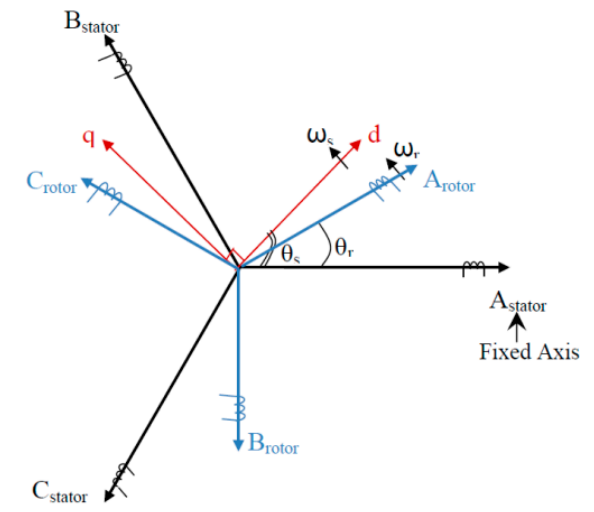

Figure 3. Phasor representation of stator and rotor axes of a DFIG.

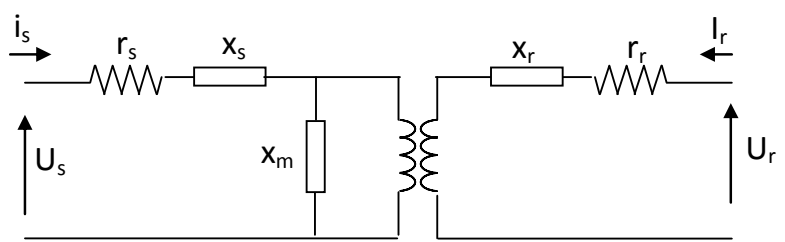

Figure 4. Equivalent circuit of a wound rotor induction generator.

Equation (1) is transformed into its $\alpha \beta$ components, $u_{\alpha}$ and $u_{\beta}$, which are orthogonal. By integrating $u_{\alpha}$ and $u_{\beta}$, the $\alpha \beta$ components of the stator flux, $\lambda_{\alpha}$ and $\lambda_{\beta}$ can be calculated and converted to the polar form, which is given by Equation (2). The angle $\theta_{s}$, gives the instantaneous position of the resultant rotating magnetic flux of the stator with respect to the phase-a fixed axis of the stator (Figure 3):

$$
\lambda=\sqrt{\lambda_{\alpha}^{2}+\lambda_{\beta}^{2}} ; \theta_{s}=\tan ^{-1}\left(\frac{\lambda_{\beta}}{\lambda_{\alpha}}\right)
$$

The model developed on this basis to find the position of the resultant rotating magnetic flux of the stator is given in Appendix A(i). The models are implemented in the well-known EMT software PSCAD (Version 4.6). In modeling, washout filters are used to remove any DC component from the integrated flux without significantly affecting the phase.

The instantaneous position of the rotor with respect to phase-a, the fixed axis of the stator (Figure 3), $\theta_{r}$ can be found by integrating the rotor speed as shown in Equation (3):

$$
\theta_{r}=\int \omega_{r d t}
$$

The rotor position with respect to stator resultant flux (stator d-Axis) can then be readily found by taking the difference between the two angles as $\left(\theta_{s}-\theta_{r}\right)$, which is known as the slip angle. The instantaneous values for the desired rotor currents $\left(I_{r a, r e f}, I_{r b, r e f}\right.$, and $\left.I_{r c, r e f}\right)$ are then calculated by taking the inverse dq transformation of $I_{d r, r e f}, I_{q r, r e f}$ with respect to the slip angle. $I_{d r, r e f}$ and $I_{q r, r e f}$ are generated at the PI controllers to get desired power flow. The model of this control mechanism of rotor currents is shown in Appendix A(ii). A voltage source converter is finally used to generate the desired rotor currents by firing the IGBTs in a hysteresis loop around $I_{r a, r e f}, I_{r b, r e f}$, and $I_{r c, r e f}$. The hysteresis current control model is shown in Appendix A(iii).

\subsubsection{Grid Side Converter Control}

A The grid side voltage source converter (VSC) is designed for maintaining a constant DC power supply, which is required for the accurate operation of the rotor side voltage source converter. The grid side VSC is shown in Figure 5. 


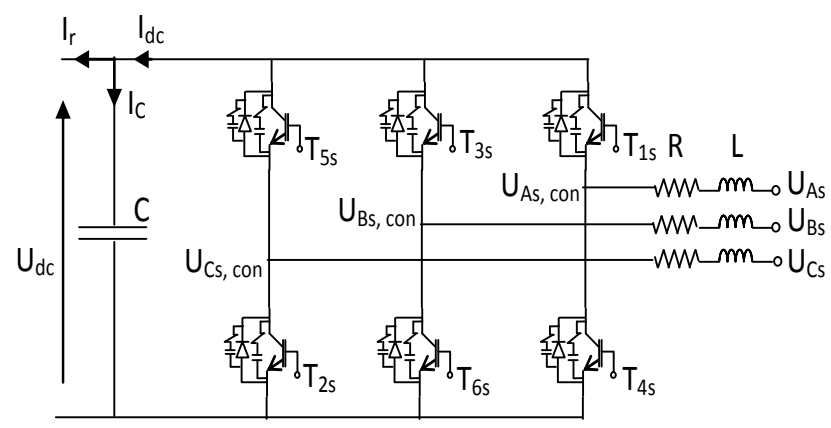

Figure 5. Grid side voltage source converter.

The AC terminals of the converter are connected to the stator through a transformer. By defining the grid instantaneous voltages (DFIG stator output voltages) as $u_{A B C}$, instantaneous currents as $I_{A B C S}$, and converter input voltages $u_{A B C s, c o n}$, and resistance, $R$ and inductance, $L$ between the converter and the grid (Figure 5), the voltage at the grid side of the converter can be expressed by Equation (4):

$$
u_{A B C s}=R I_{A B C S}+L \frac{\mathrm{d} I_{A B C s}}{\mathrm{~d} x}+u_{A B C s, c o n}
$$

The relationship between the phase voltages and the currents in (4) is transformed to the dq-frame. This transformed relationship is shown in Equation (5). For the stator side voltage source converter control, the $\mathrm{d}$-axis is defined to be along the direction of grid voltage vector. Therefore, a virtual grid flux vector can be assumed to act along the q-axis, making $u_{s q}=0$ :

$$
\frac{\mathrm{d}}{\mathrm{d} t}\left[\begin{array}{c}
I_{s d} \\
I_{s q}
\end{array}\right]=\left[\begin{array}{cc}
-\frac{R}{L} & \omega \\
-\omega & \frac{R}{L}
\end{array}\right]\left[\begin{array}{c}
I_{s d} \\
I_{s q}
\end{array}\right]+\frac{1}{L}\left[\begin{array}{c}
u_{s d}-u_{d, c o n} \\
u_{s q}-u_{q, c o n}
\end{array}\right]
$$

The power balance relationship between the AC input and DC output of the grid side converter is given by Equation (6), where $U_{d c}$ and $I_{d c}$ are DC output voltage and current, respectively:

$$
P=\frac{3}{2}\left(u_{d, c o n} I_{s d}+u_{q, c o n} I_{s q}\right)=U_{d c} I_{d c}
$$

With reference to Figure 5, by applying Kirchoff's current law at the DC capacitor connection point, the relationship between the DC output current and voltage can be found:

$$
I_{d c}=C \frac{\mathrm{d}}{\mathrm{d} t} U_{d c}+I_{r}
$$

By substituting for $I_{d c}$ in Equation (6) from Equation (7), it can be shown that DC voltage can be regulated by controlling d-axis current, $I_{s d}$. However, Equation (5) shows that, when attempting to change the d-axis current, $I_{s d}$ using $u_{s d}$, the q-axis current, $I_{s q}$ also changes. Therefore, in the control mechanism, decoupling of d-axis and q-axis is achieved by correcting the error in $I_{s d}$ through a change in $\left(u_{s d}+\omega L I_{s q}\right)$ and error in $I_{s q}$ through a change in $\left(u_{s q}-\omega L I_{s d}\right)$ [6]. This generates the voltage references, $u_{d s r e f}$ and $u_{d s, \text { ref }}$ components of stator voltages for controlling the DC voltage. The corresponding phase values $u_{A s, r e f}, u_{B s, r e f}, u_{C s, r e f}$ can be found by inverse dq transformation. The model developed for DC voltage control is shown in Appendix A(iv).

The $\mathrm{dq}$ transformations of currents and voltages require stator voltage vector direction, and this can be found by taking the $\alpha \beta$ conversion of stator voltages $u_{A B C s}$. A standard sinusoidal PWM converter is used to generate the voltages defined by the respective references values, $u_{A s, r e f}, u_{B s, r e f}$ $u_{C S, r e f}$, which are derived for controlling the DC voltage. In the Pulse Width Modulation (PWM) controller, each of the reference phase voltages is compared with a high frequency triangle wave to 
determine the firing pulse patterns. The method used for generating PWM firing pulses is shown in Appendix A(v).

\subsection{Average DFIG Model}

The previous section illustrated the modeling of the DFIG control as a detailed system. However, detailed modeling of the DFIG involves modeling the firing of switching devices (usually IGBTs), and as a result, incurs high computational cost.

Therefore, development of an average model of DFIG, which excludes the switching models, is important for certain types of studies such as transient stability assessment. These studies demand multiple runs of long duration simulations. In the discussion on the standard detailed model of DFIG presented in Section 2.1, it was indicated that the rotor side converter injects currents into the rotor winding acting as a current source, and the stator side converter charges the DC bus capacitor to maintain a constant DC voltage, which thus, acts as a voltage source. This concept can directly be used in the development of the average model of DFIG.

The equivalent circuit of the back-to-back converter in the DFIG can be represented as shown in Figure $6[10,11]$. In modeling the average representation of DFIG system, only the converters are replaced with corresponding current sources and voltage sources while the control strategy is kept unchanged. The instantaneous values for the desired rotor currents $\left(I_{r a, r e f}, I_{r b}\right.$ ref, and $\left.I_{r c ~ r e f}\right)$ generated by the controls in rotor side are directly injected into the rotor by using current sources. However, the reference signals were delayed in accordance with the IGBT switching delays in the detailed model. The model thus developed is shown in Appendix B(i).

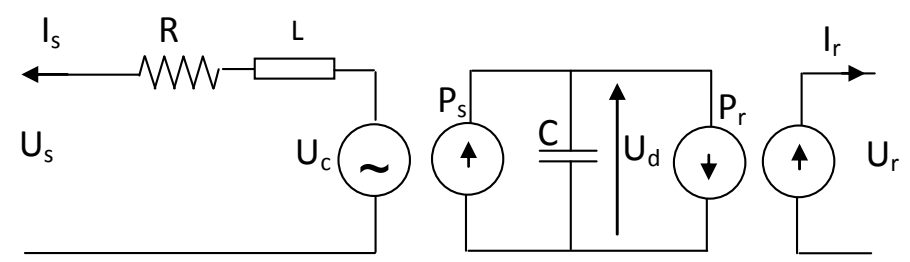

Figure 6. Equivalent circuit of the back-to-back converters in the DFIG.

The instantaneous voltage references, $u_{A s, r e f}, u_{B s, r e f}, u_{C s, r e f}$ required to maintain the constant DC voltage, $U_{d}$ are generated at the stator side controllers. If $U_{s}$ is the RMS value of AC system (stator) voltage, $U_{c}$ is the RMS value of the fundamental frequency component of the grid side voltage source converter output voltage and $m$ is the modulation index, then the relationship between $U_{c}$ and $U_{d}$ can be given by Equation (8) [12].

$$
\begin{gathered}
U_{c}=\frac{m}{\sqrt{2}} U_{d} \\
m=\frac{U_{s A B C, \text { ref, peak }}}{U_{\text {carrier, peak }}}
\end{gathered}
$$

The modulation index $m$, is defined as given in (9). If the carrier signal peak is 1 per units (pu) and the instantaneous voltage references are specified in per-units $(\mathrm{pu})$, then the modulation index at each phase is equal to the peak value of the instantaneous voltage references, $u_{A s, r e f}, u_{B s, r e f}, u_{C s, r e f}$. Therefore, to meet the requirement in (8), the instantaneous values, $u_{A c, \text { ref }}, u_{B c, \text { ref }}, u_{C c, \text { ref }}$ that need to be specified in the voltage sources, which replace the voltage source converter at the stator side are given by Equation (10). The model corresponding to grid side voltage sources is shown in Appendix B(ii). The voltage reference signals were also delayed in accordance with the IGBT switching delays in the detailed model:

$$
u_{A B C c, \text { ref }}=u_{A B C s, \text { ref }} U_{d} U_{s, b a s e}
$$


In order to emulate the effects of DC voltage control at the capacitor through the grid side converter and power supply to rotor side converter, AC and DC power balance is considered. Therefore, the reference DC current injected from the grid side is calculated by dividing the instantaneous $\mathrm{AC}$ power, $P_{s}$ by the DC voltage $U_{d}$. Similarly, reference DC current absorbed by the rotor side current source is calculated. The model developed for emulating DC bus voltage is given in Appendix B(iii).

\section{Model Validation}

The designed average model was validated against the standard detailed model of DFIG using the simple test system shown on Figure 7. The standard wound rotor induction generator model available in the PSCAD/EMTDC is used by configuring the parameters according to [13]. The wind turbine is modeled assuming constant power co-efficient and maximum power tracking, which was configured with reference to [14]. A weak $138 \mathrm{kV}$ utility grid with $6 \Omega \angle 85^{\circ}$ equivalent impedance feeding a $13.2 \mathrm{kV}$ radial line through a $25 \mathrm{MVA}, 138 / 13.2 \mathrm{kV}$ transformer was considered. Simulations were carried out for both balanced and unbalanced loads, connected at the DFIG terminal. Crow-bar protection was not considered in this study.

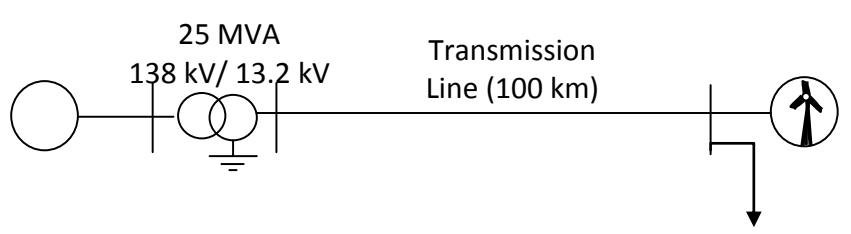

Figure 7. Simple test system to validate the average model.

Three scenarios were considered with both balanced and unbalanced loads for model validation:

Scenario 1 a 3-phase to ground fault of $0.1 \Omega$ at the DFIG terminal.

Scenario 2 a 3-phase to ground fault of $0.1 \Omega$ at the high voltage $(\mathrm{HV})$ side of the substation transformer.

Scenario 3 wind speed change from $11.5 \mathrm{~ms}^{-1}$ to $10.5 \mathrm{~ms}^{-1}$ and back to $11.5 \mathrm{~ms}^{-1}$.

\subsection{Scenarios 1, 2 and 3 with Balanced Loads}

Simulation results for the three scenarios with a balanced load of $0.7 \mathrm{MW}, 0.5$ MVar per phase are shown in the Figures 8-10, respectively. Figure 8 shows the power outputs, load bus voltage, DC voltage and DFIG speed for both average and detailed models of DFIG for a 3-phase to ground fault of $0.1 \Omega$ at the DFIG terminal (scenario 1 ) with balanced loads.

When active power outputs (Figure 8a), reactive power outputs (Figure 8b), and the load bus RMS voltage (Figure $8 \mathrm{c}$ ) are considered, DFIG detailed model and the average model presents almost identical behaviours.

Also, DC voltage measured at the grid side voltage controller (Figure 8d) and the DFIG speed (Figure 8e) show similar behaviour when the detailed and the average DFIG models are compared. The deviations observed during transients would be comparatively higher if the IGBT switching delays were not considered in the average model. It was further observed that the rotor angle variations in the two cases were slightly different during the transients, which would introduce variations in the control signals resulting slight differences in the DC voltage and the speed waveforms for the detailed and average models during transients.

Very similar results were noted when a 3-phase to ground fault of $0.1 \Omega$ occurs at the HV side of the substation transformer (Scenario 2) with the balanced load. Figure 9 illustrates the corresponding plots of the power outputs, load bus voltage, DC voltage and DFIG speed for both average and detailed model of the DFIG. In Scenario 3, with the balanced load, wind speed was changed from 
$11.5 \mathrm{~ms}^{-1}$ to $10.5 \mathrm{~ms}^{-1}$ and back to $11.5 \mathrm{~ms}^{-1}$. Figure 10 illustrates the power outputs, load bus voltage, DC voltage, and DFIG speed for both average and detailed models of the DFIG. With the small disturbance, switching transients at the converters are negligible and thus, gives similar variations of the control reference signals $I_{d}$ and $I_{q}$ at the rotor side, and $V_{d}$ and $V_{q}$ at the stator side for both average and detailed models of the DFIG. The measured rms voltages at the load bus show nearly $0.001 \mathrm{pu}$ deviation in the steady state when comparing the detailed and average models.

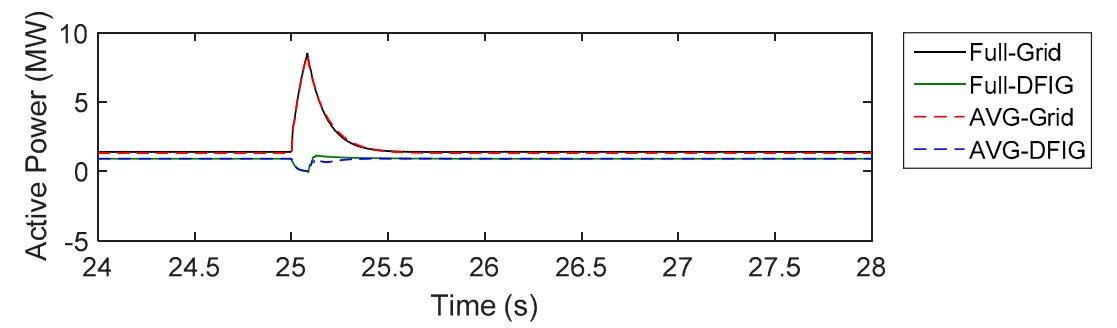

(a)

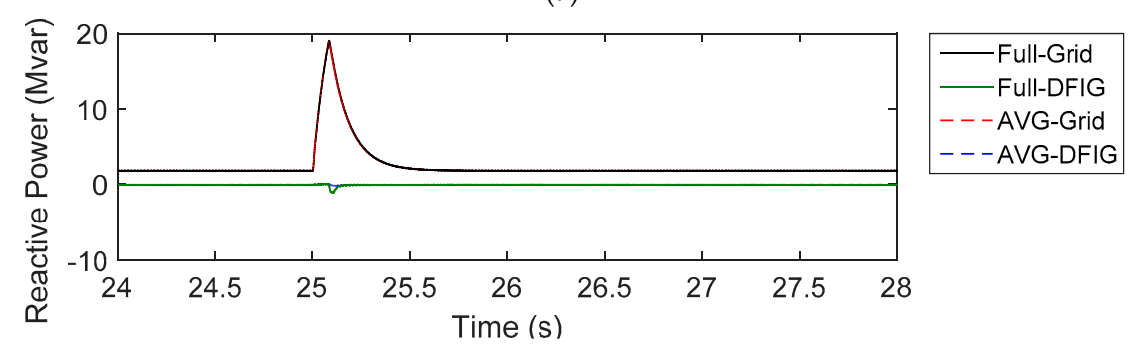

(b)

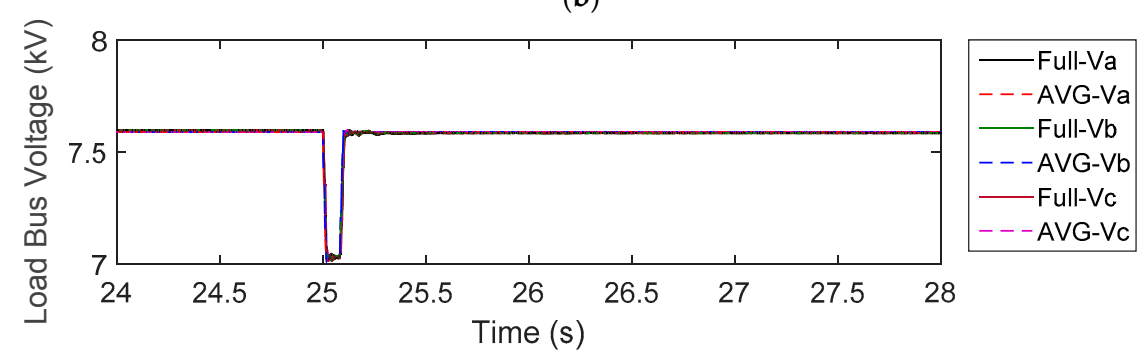

(c)

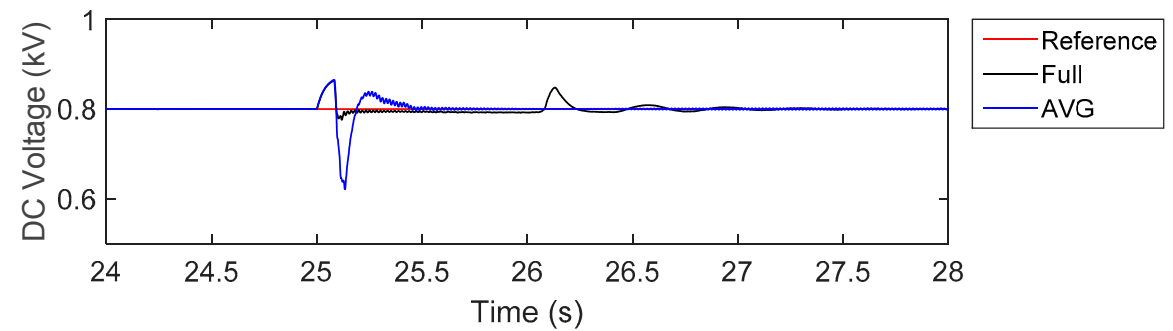

(d)

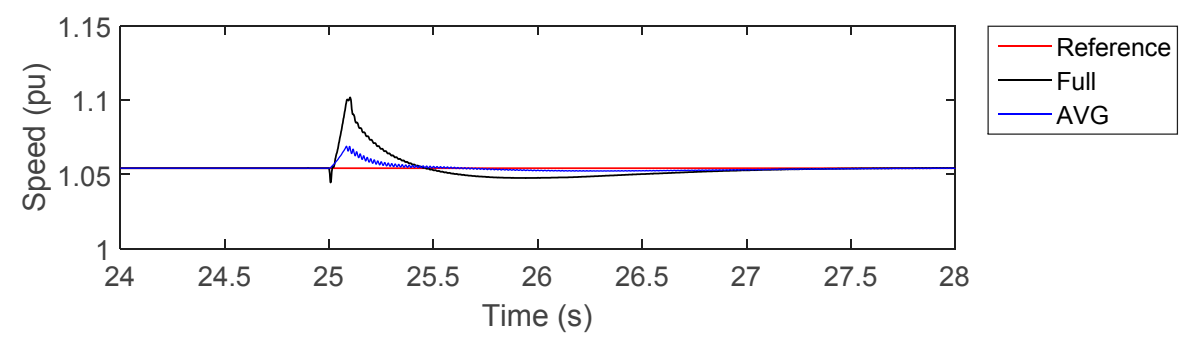

(e)

Figure 8. Outputs with 3-phase to ground fault of $0.1 \Omega$ at the DFIG terminal with balanced loads: (a) active power outputs, (b) reactive power outputs, (c) load bus voltage, (d) DC voltage, (e) DFIG speed. 

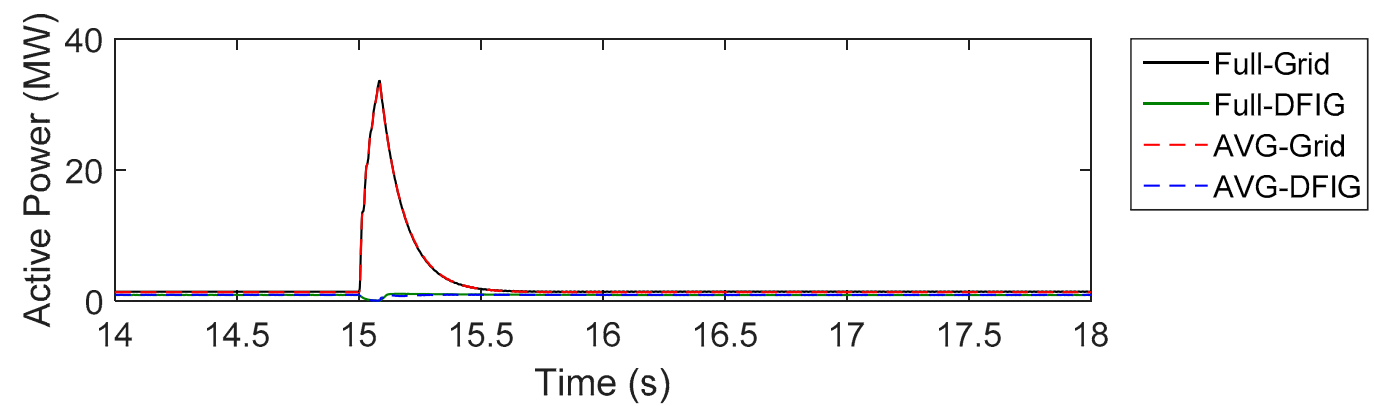

(a)
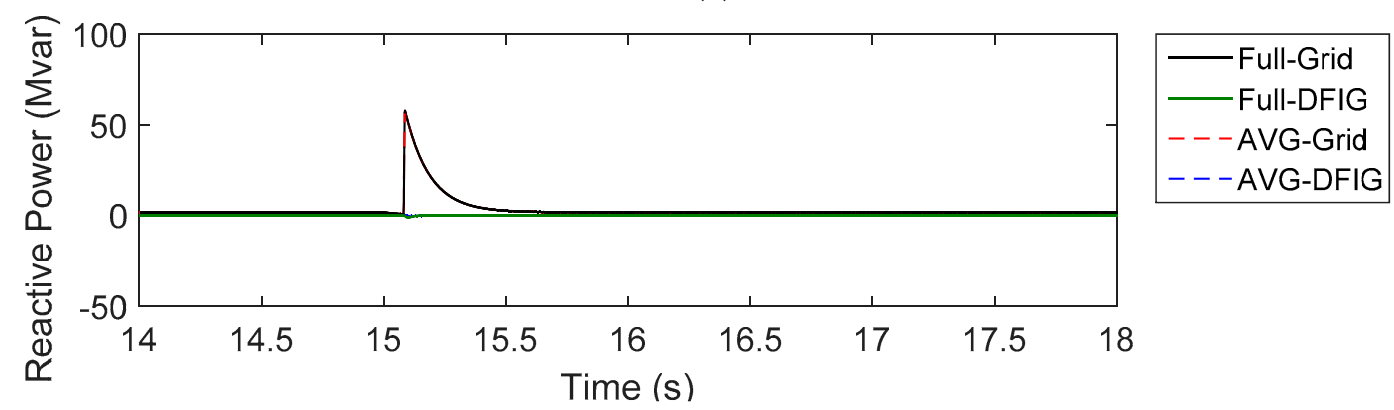

(b)
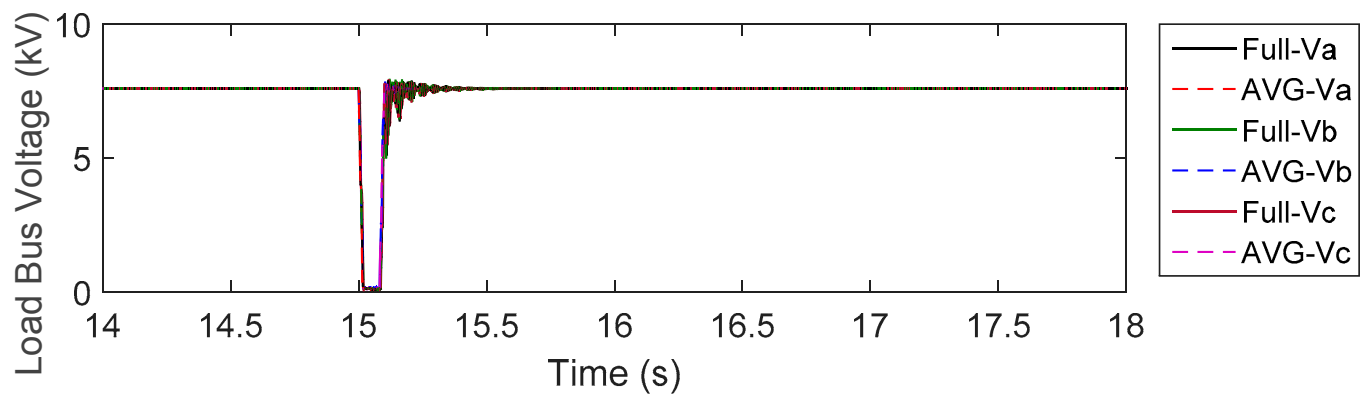

(c)
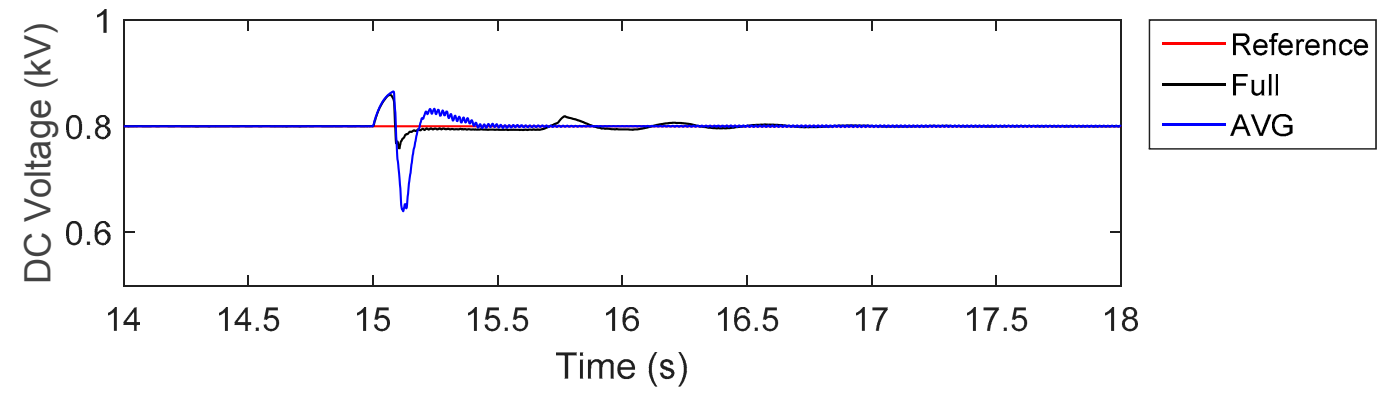

(d)
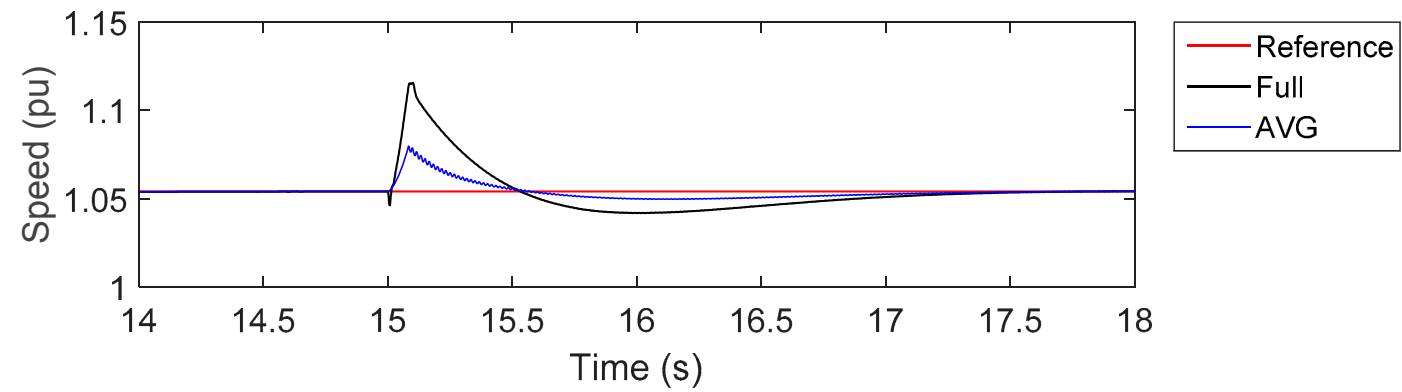

(e)

Figure 9. Outputs to ground fault of $0.1 \Omega$ at HV side of substation transformer with balanced loads: (a) active power outputs, (b) reactive power outputs, (c) load bus voltage, (d) DC voltage, (e) DFIG speed. 

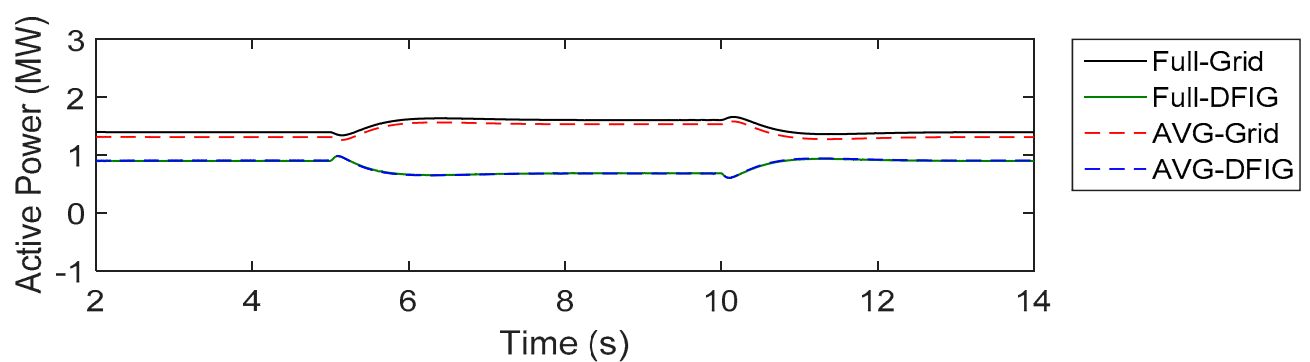

(a)
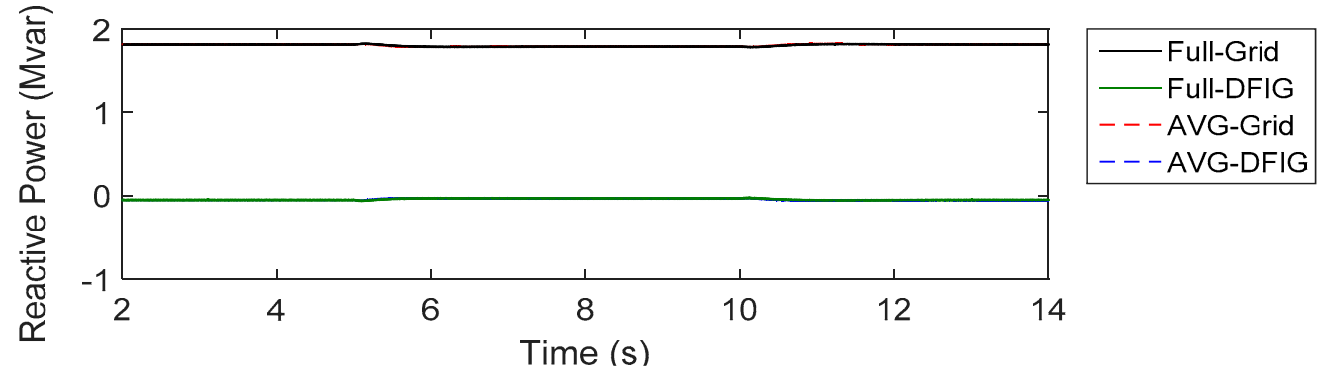

(b)

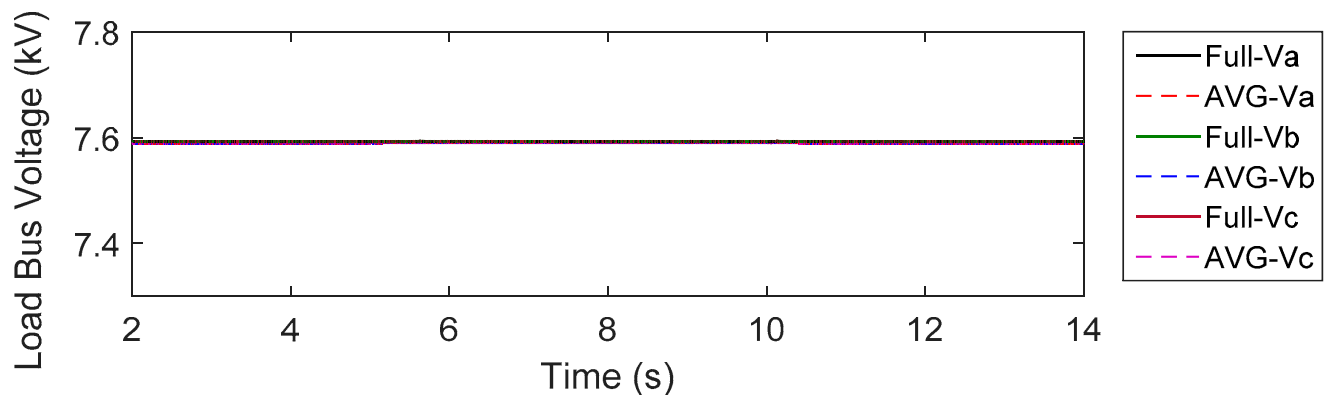

(c)

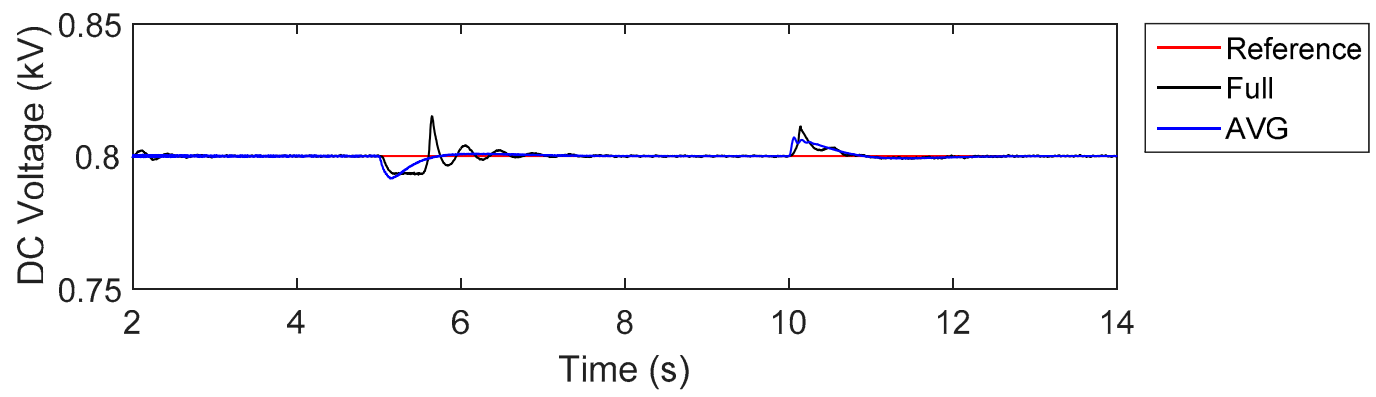

(d)

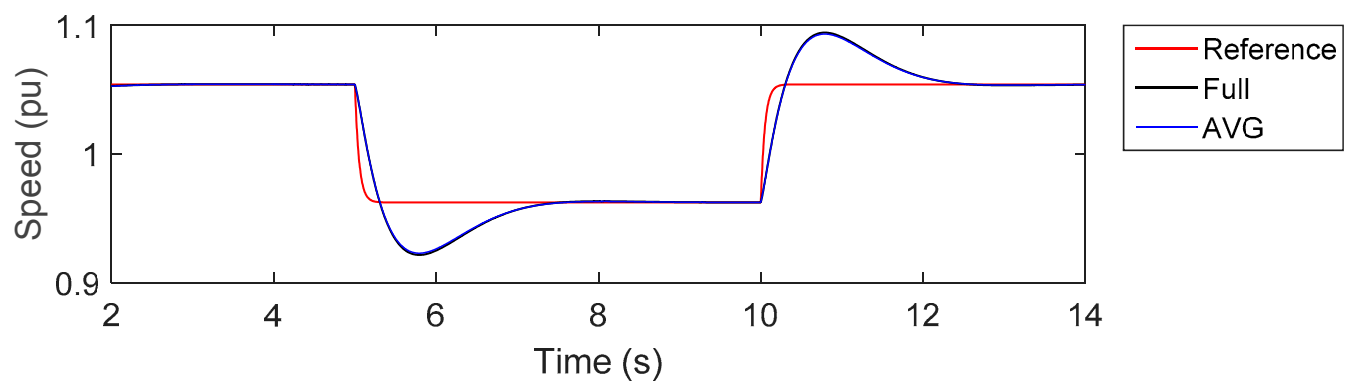

(e)

Figure 10. Outputs when wind speed change of $11.5 \mathrm{~m} / \mathrm{s}$ to $10.5 \mathrm{~m} / \mathrm{s}$ back to $11.5 \mathrm{~m} / \mathrm{s}$ with balanced loads connected to DFIG Bus: (a) active power outputs, (b) reactive power outputs, (c) load bus voltage, (d) DC voltage, (e) DFIG speed. 


\subsection{Scenarios 1, 2 and 3 with Unbalanced Loads}

With the aim of investigating the effect of load unbalance on the DFIG controls and on the average model, above three case studies were repeated by replacing the total balanced load with an unbalanced load comprised of 0.7 MW, 0.5 MVar in phase-a; 1.1 MW, 0.79 MVar in phase-b and 0.3 MW, 0.21 MVar in phase-c. Simulation results for the three cases: 3-phase to ground fault of $0.1 \Omega$ at the DFIG terminal (Scenario 1), 3-phase to ground fault of $0.1 \Omega$ at HV side of substation transformer (Scenario 2) and a wind sped change of $11.5 \mathrm{~ms}^{-1}-10.5 \mathrm{~ms}^{-1}-11.5 \mathrm{~ms}^{-1}$ (Scenario 3) with the unbalanced load are shown in Figures 11-13, respectively.
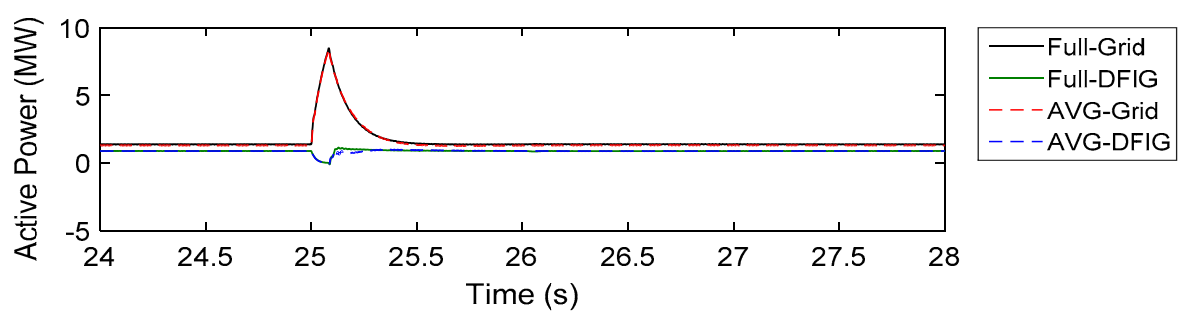

(a)

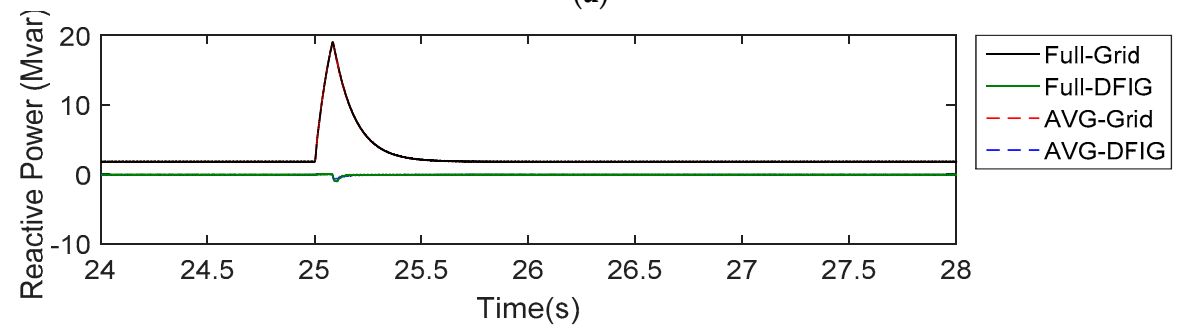

(b)

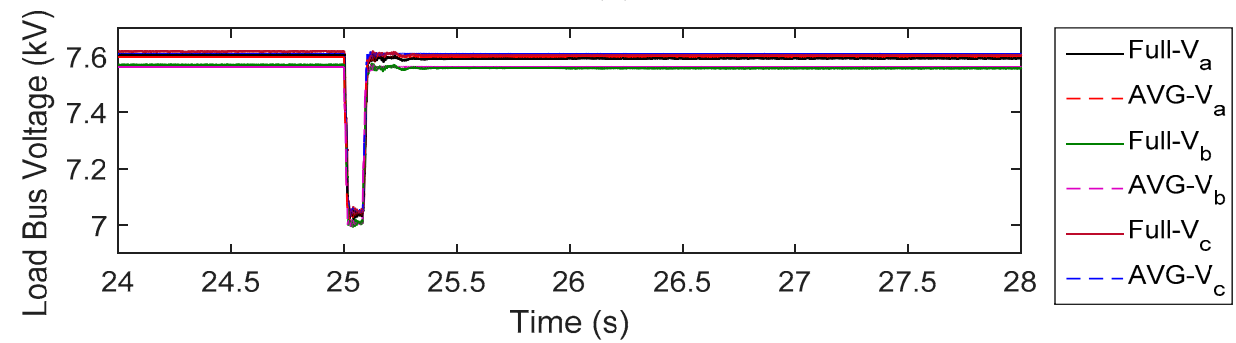

(c)

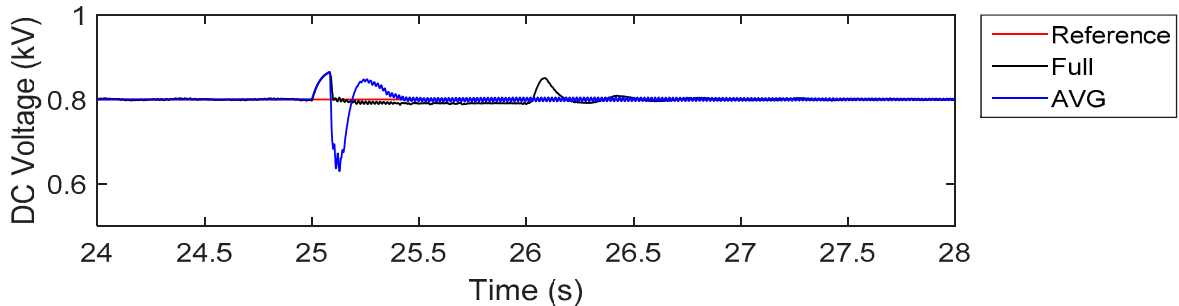

(d)

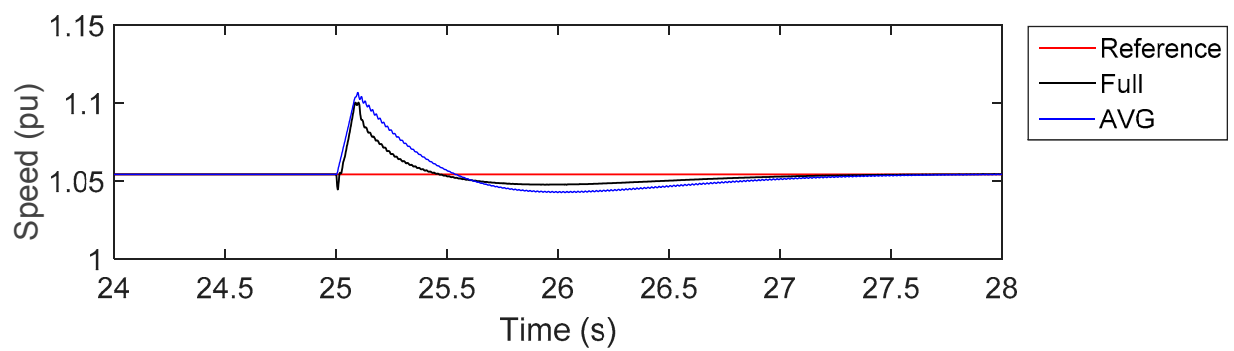

(e)

Figure 11. Cont. 


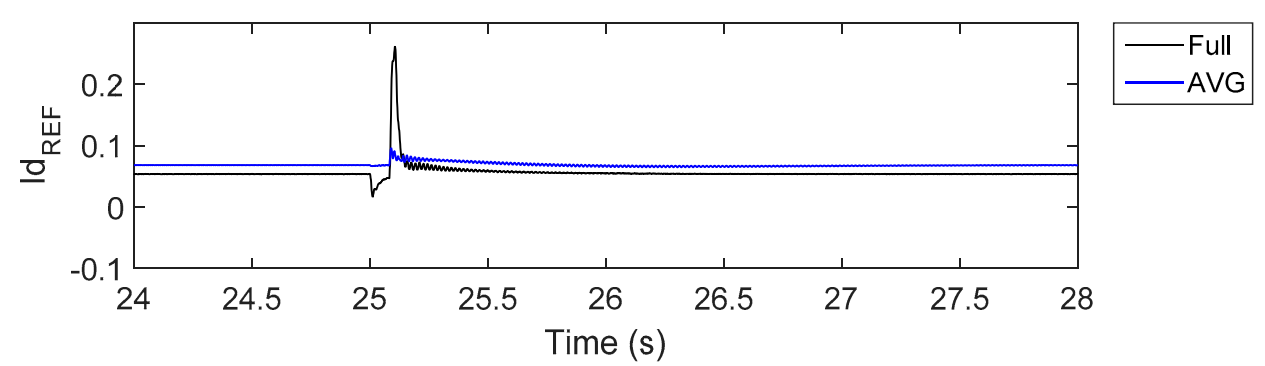

(f)
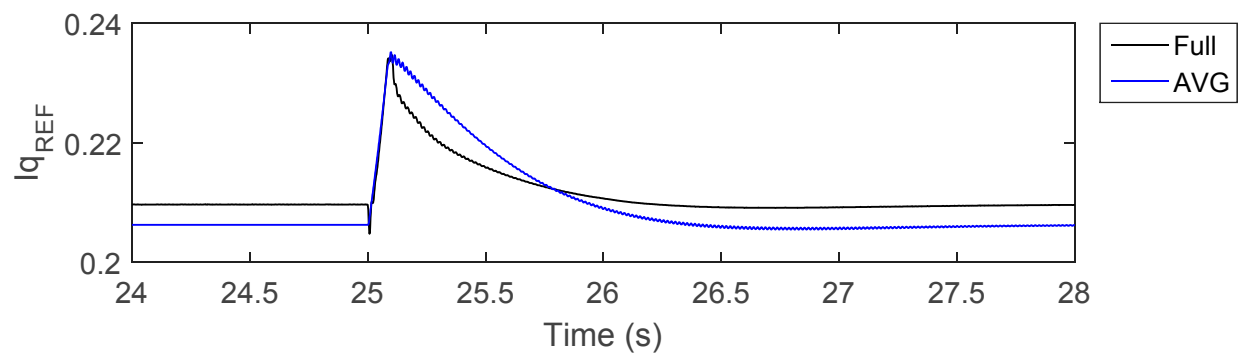

(g)

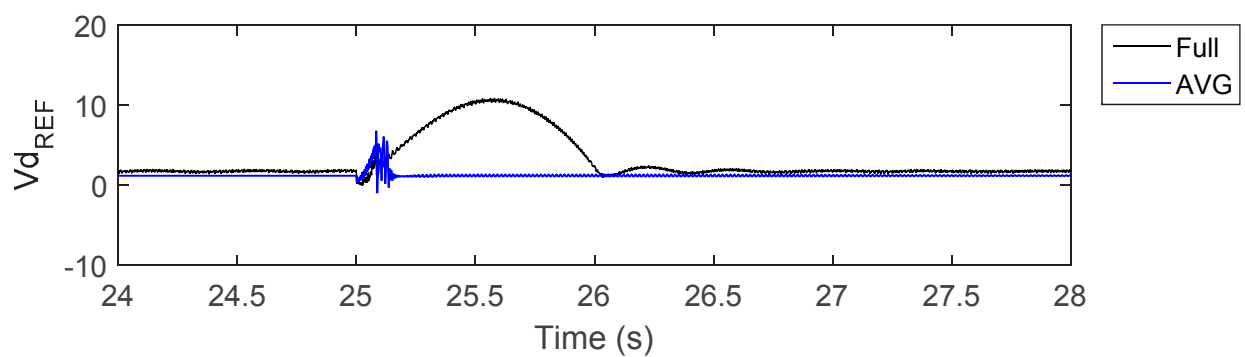

(h)

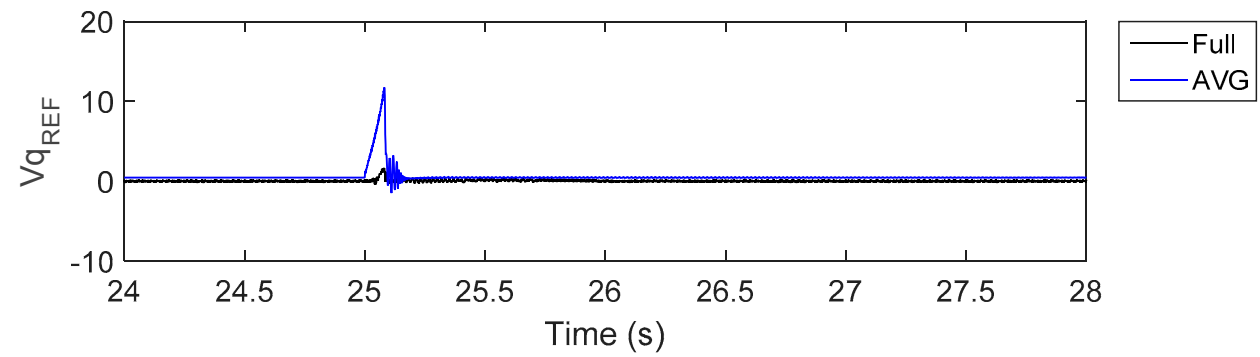

(i)

Figure 11. Outputs with 3-phase to ground fault of $0.1 \Omega$ at the DFIG terminal with unbalanced loads: (a) active power outputs, (b) reactive power outputs, (c) load bus voltage, (d) DC voltage, (e) DFIG speed, (f) control reference signals $I_{d}$ at the rotor side, (g) control reference signals $I_{q}$ at the rotor side, (h) control reference signals $V_{d},(\mathbf{i})$ control reference signals $V_{q}$.

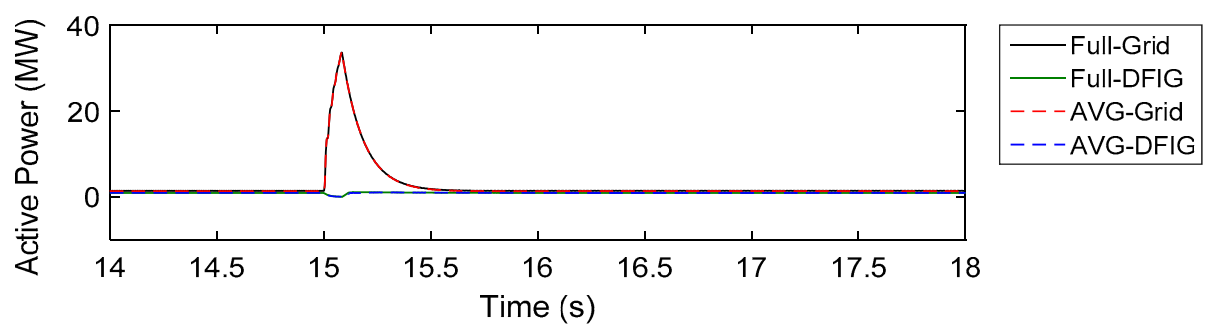

(a)

Figure 12. Cont. 


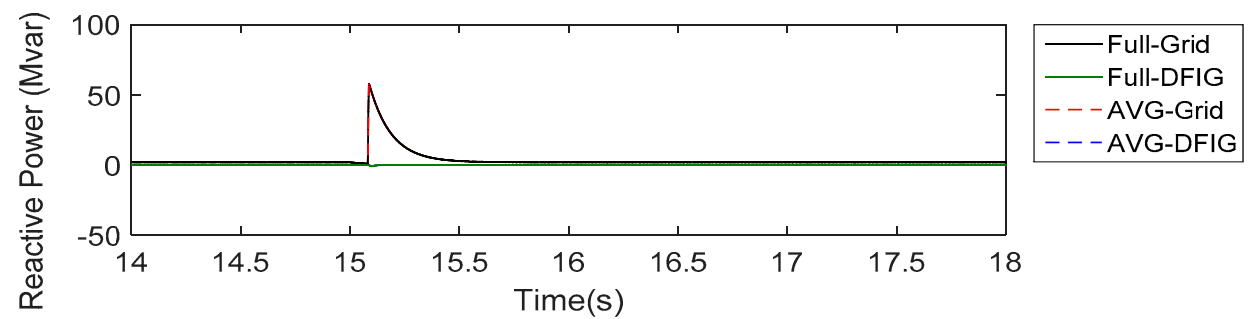

(b)

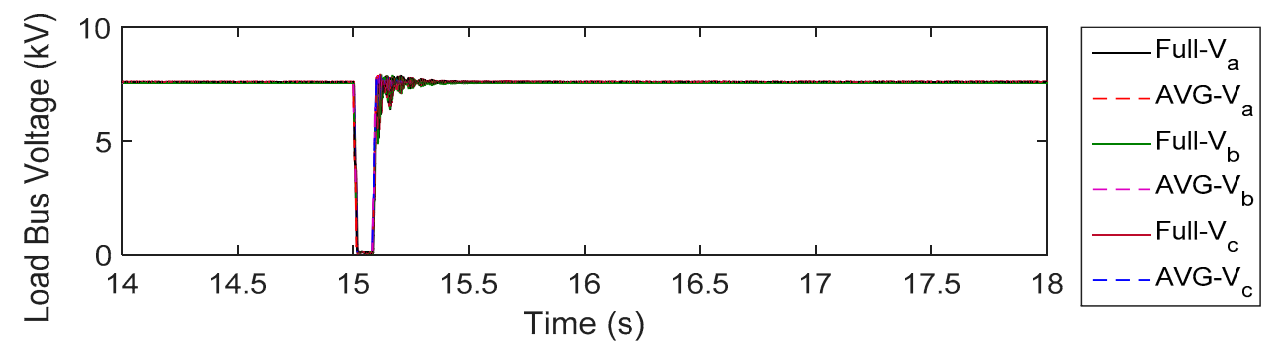

(c)

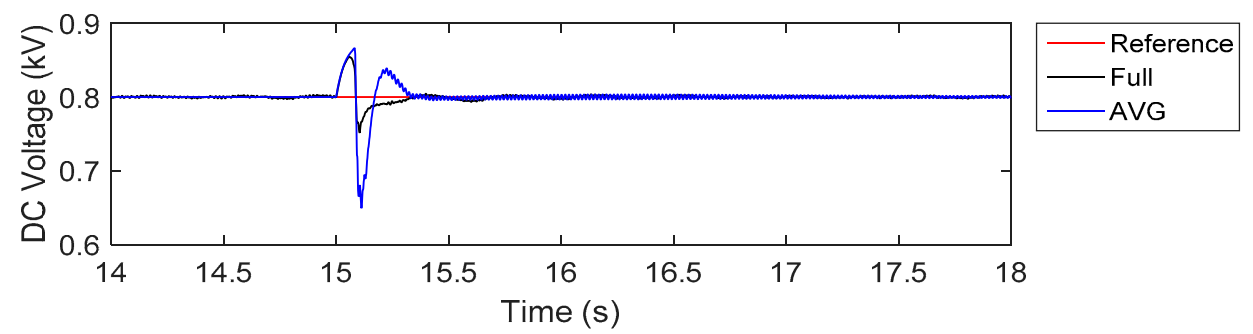

(d)

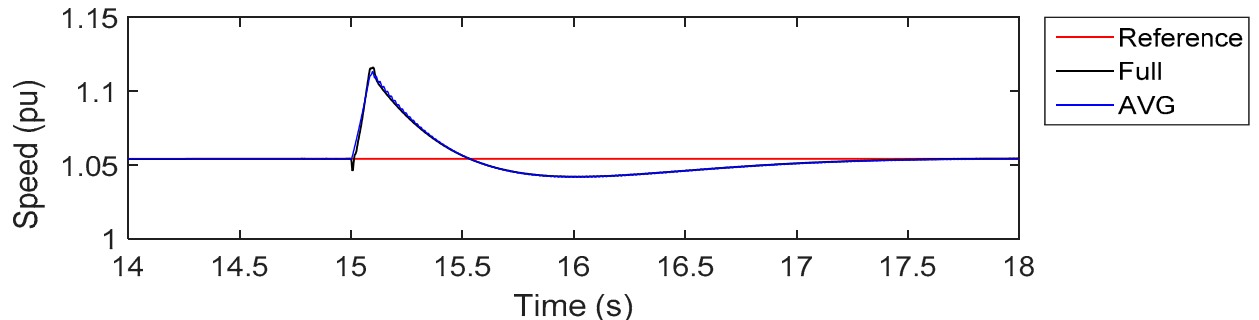

(e)

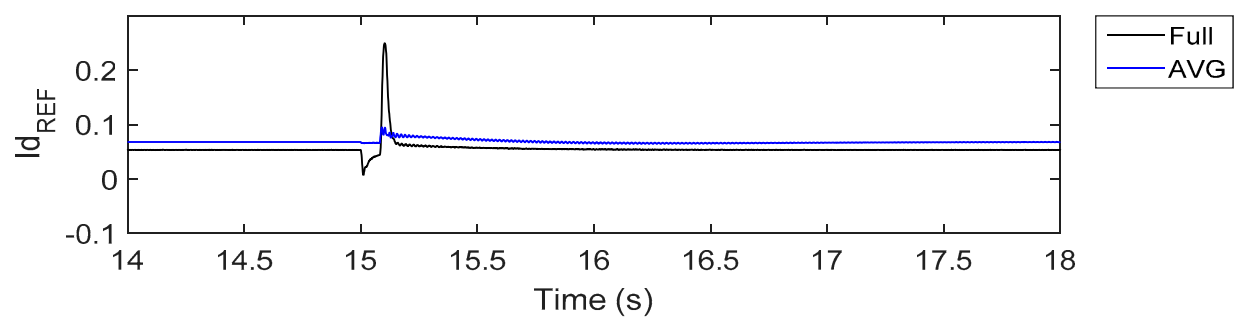

(f)

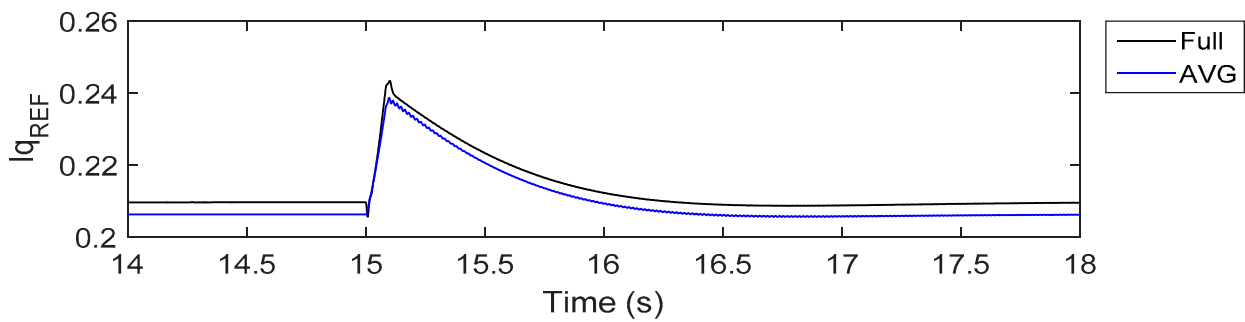

(g)

Figure 12. Cont. 


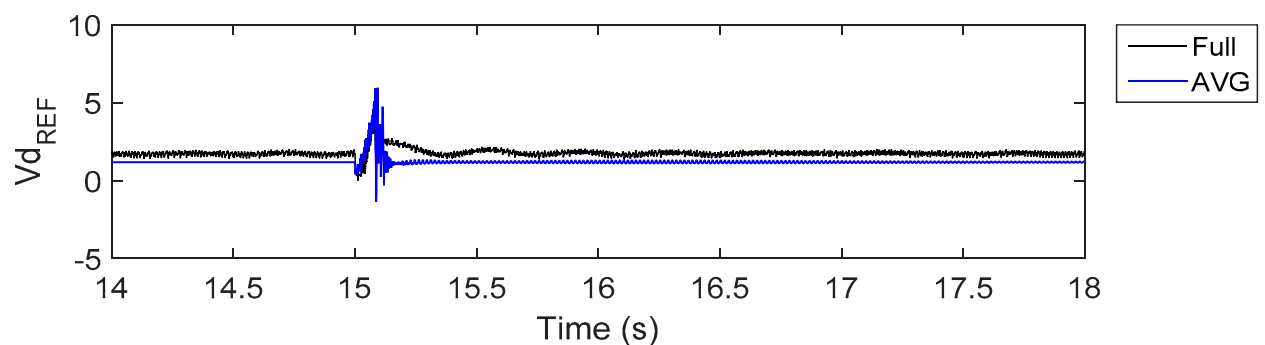

(h)

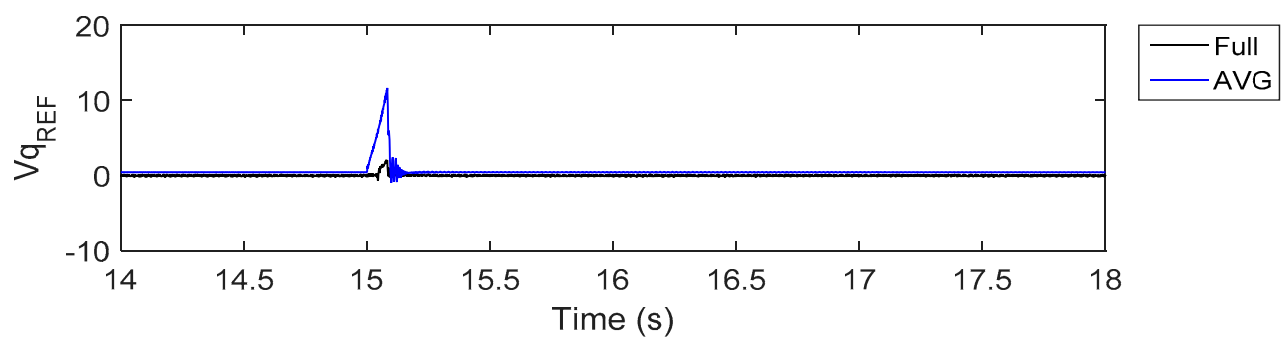

(i)

Figure 12. Outputs with 3-phase to ground fault of $0.1 \Omega$ at HV side of substation transformer with unbalanced loads connected to DFIG Bus: (a) active power, (b) reactive power, (c)load bus voltage, (d) DC voltage, (e) DFIG speed, (f) $I_{d}$ at the rotor side, $(\mathrm{g}) I_{q}$ at the rotor side, (h) $V_{d},(\mathbf{i}) V_{q}$.

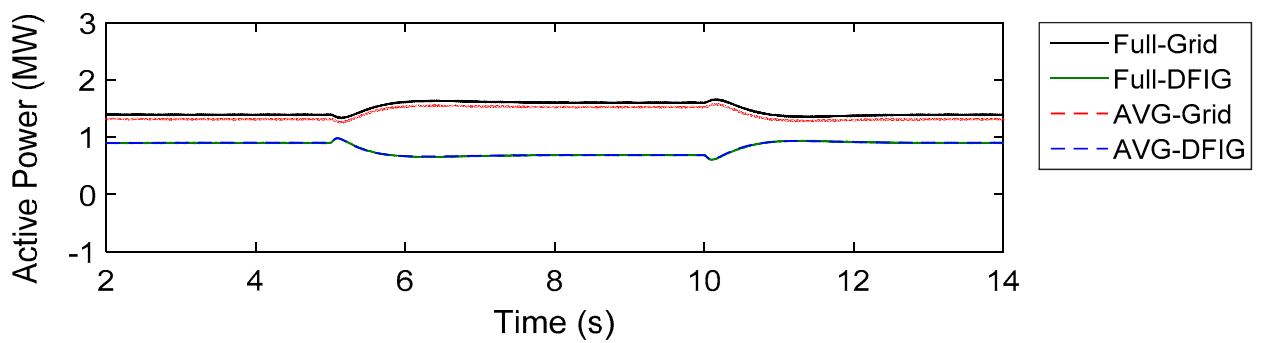

(a)

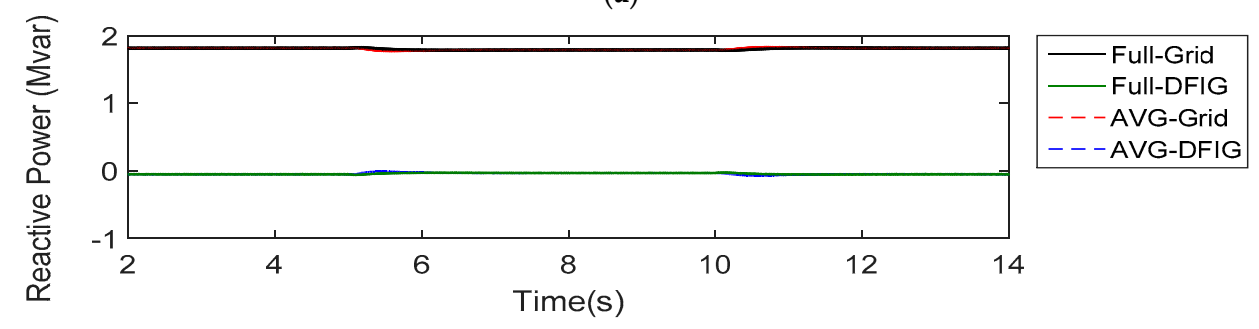

(b)

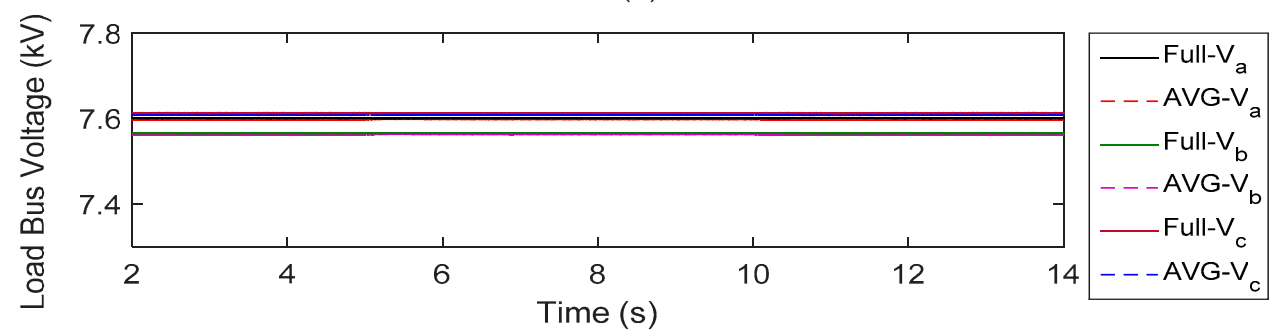

(c)

Figure 13. Cont. 


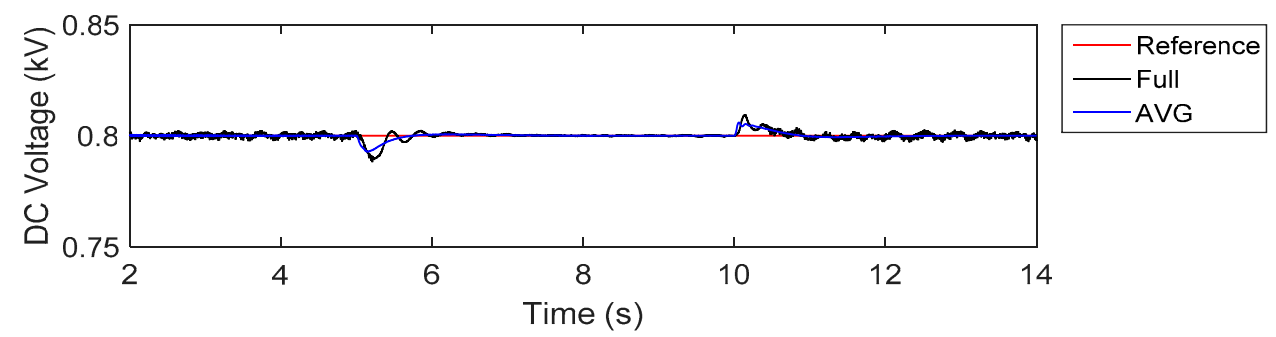

(d)

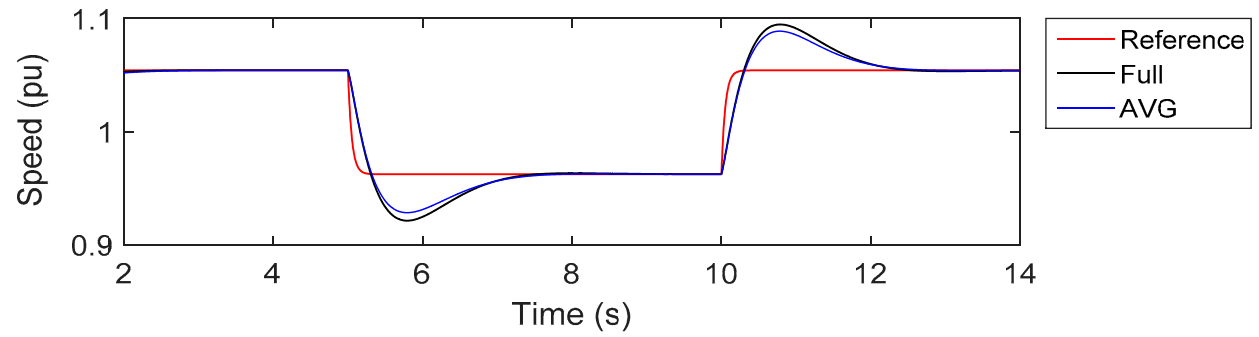

(e)

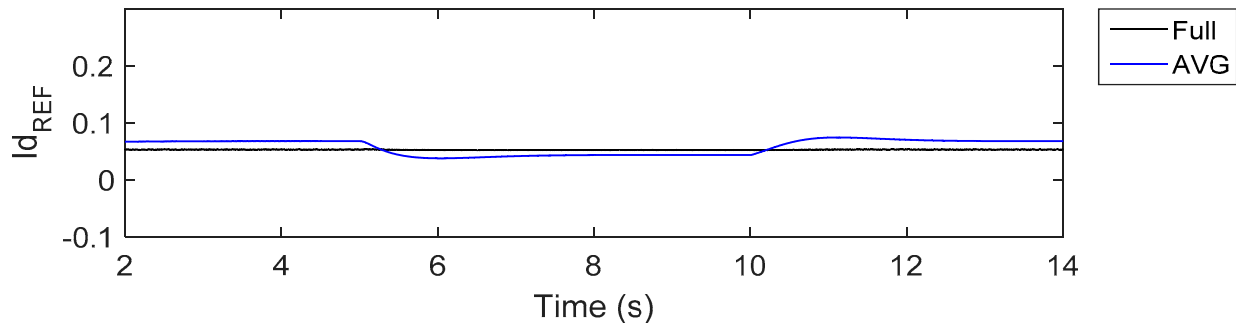

(f)
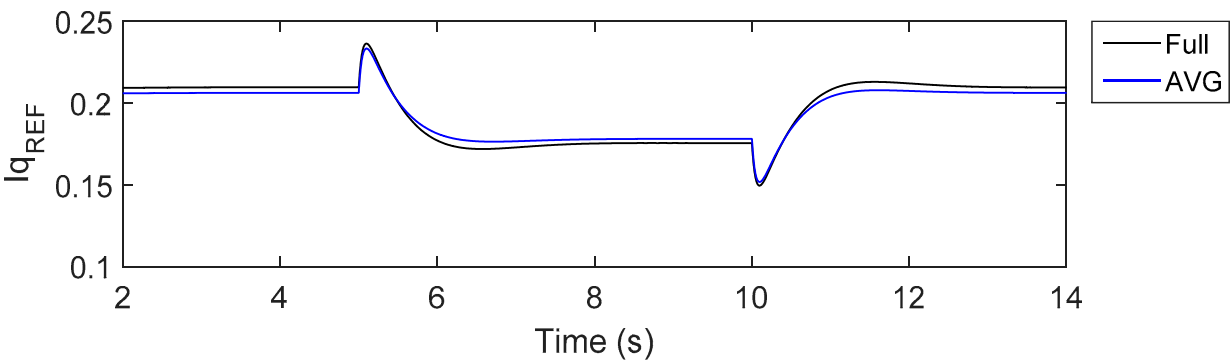

(g)

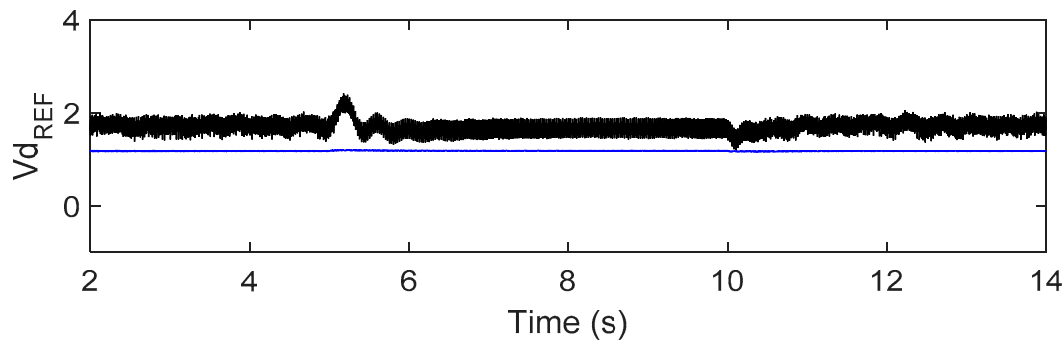

Figure 13. Cont. 


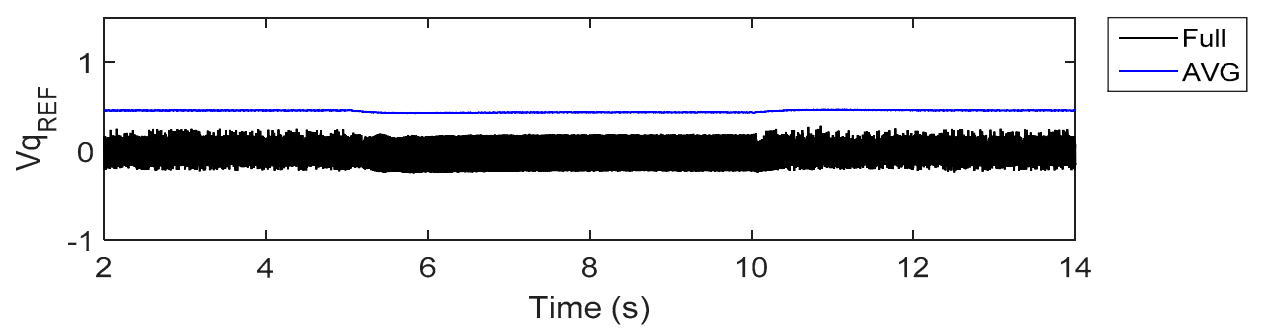

(i)

Figure 13. Outputs when wind speed change of $11.5 \mathrm{~m} / \mathrm{s}$ to $10.5 \mathrm{~m} / \mathrm{s}$ back to $11.5 \mathrm{~m} / \mathrm{s}$ with unbalanced loads connected to DFIG Bus. (a) active power outputs, (b) reactive power outputs, (c) load bus voltage, (d) DC voltage, (e) DFIG speed, (f) $I_{d},(\mathbf{g}) I_{q},(\mathbf{h}) V_{d},(\mathbf{i}) V_{q}$.

The average model gives near identical outputs as standard detailed model of the DFIG. The designed average model performs well under both balanced and unbalanced loads, but may show some variation in the bus voltage levels in the steady state operation if the system is unbalanced. The steady state voltage at the load bus shows that the variation between the observed RMS voltages with the average and detail models has increased to $0.005 \mathrm{pu}$. This was about $0.001 \mathrm{pu}$ from the balanced load. Compared to the balanced loads case, with unbalanced loads, DC voltage and DFIG speed waveforms are very much comparable for detailed and average models of DFIG.

In the average model, the convertors were replaced with current and voltage sources and the DC voltage control was replaced accordingly with the power balance relationship. PID control settings were kept same as it is for the detailed DFIG model. When looking at the control reference signals $I_{d}$ and $I_{q}$ at the rotor side (Figure 11f,g), and $V_{d}$ and $V_{q}$ at the stator side (Figure 11h,i), they show that the transients observed with the detailed model has a higher time constant as well as a magnitude than those with the designed average DFIG model. Although there are snubber-circuits modeled in the IGBTs of the converters in the detailed model, still with the flyback topology, IGBT switching introduces higher transients in the detailed DFIG model. Moreover, the estimated phase angles used for $\mathrm{d}$-q transformation slightly differ in the detailed model due to higher order harmonics/noise. That results in differences in d- and q axes reference quantities of the two models, and manifest as differences in machine speeds.

\section{Application of DFIG in a Microgrid System}

To further verify the accurate operation of the DFIG controls of the standard DFIG model and the designed average model of DFIG, their application in a MV microgrid test system was analyzed under steady state and transient operation conditions.

The microgrid test system shown in the Figure 14 [15] was used in this section by replacing the fixed speed wind turbine explained in [15] with the DFIG detail/average model. Solar PV model that was in [15] was also eliminated to highlight the effects of DFIG. The microgrid was derived from the proposed CIGRE MV benchmark test system [16].

The test system was simulated and tested using PSCAD/EMTDC, power system simulation software using a simulation time step of $5 \mu$ s [17]. The loads are highly unbalanced with Phase-b having the greatest load. As shown in Figure 14, there is a 3 MW steam turbine-driven synchronous generator connected to Bus-10, and a 1 MW wind turbine-driven DFIG connected to Bus-7.

The DGs are placed considering the recommendations made in [16], and the load flow of the system without DGs (Bus-10 is one of the weakest buses without DGs). A high capacity, higher inertia DG (the synchronous generator) is used to avoid the necessity of an energy-storage. Control scheme of the microgrid is discussed in [15]. Simulation studies were carried out considering that the power output of synchronous generator, and the wind turbine were at $0.83 \mathrm{pu}$, and $0.9 \mathrm{pu}$ respectively when the microgrid is grid connected. 


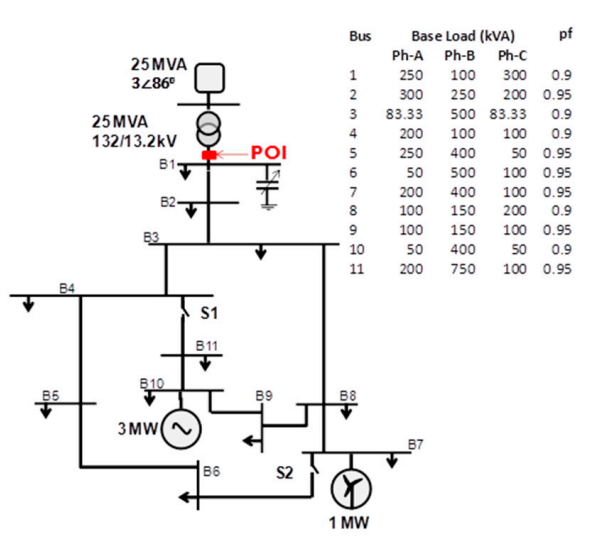

Figure 14. Microgrid test system.

\subsection{Steady State Operation of the Microgrid}

Figure 15 presents the PSCAD steady state bus voltages (RMS) when the microgrid is grid connected. The results show that the detailed design of DFIG and average design of DFIG are highly comparable against each other giving a maximum voltage error less than $0.02 \%$.

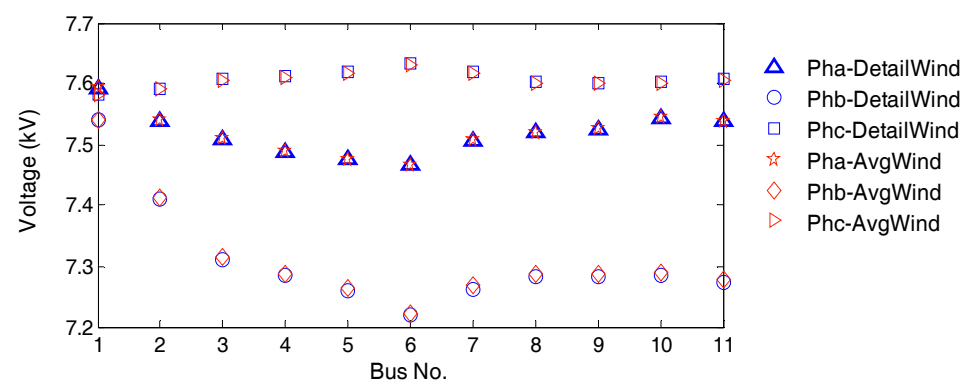

Figure 15. Comparison of steady state Phase voltages of busses with standard detailed and average models of DFIG when the microgrid is grid connected.

The microgrid was islanded by opening the breaker at the POI (Figure 14), after a predefined time. The system undergoes a transient state with load shedding before achieving the new stable operating point. The switched capacitors were also operated according to the set voltage criteria.

The RMS phase voltages for the steady state islanded operation of the microgrid without switching the capacitors (for voltage correction in the system) are presented in Figure 16. Results are shown for both detailed and average DFIG designs. Considering the results with the detailed model of the DFIG shown in Figure 16, there is nearly $12.5 \%$ voltage deviation from the nominal voltage $(7.621 \mathrm{kV})$ at Bus-6, which is the weakest bus, and the voltage unbalance is above $5 \%$.
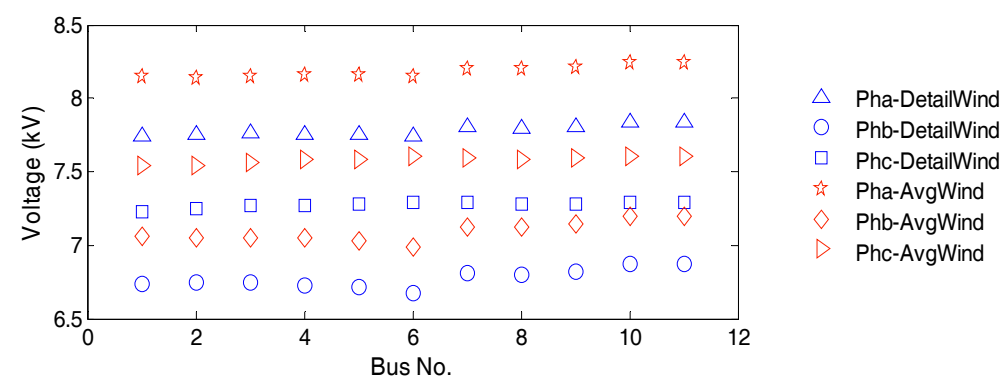

Figure 16. Comparison of DFIG models in steady state operating phase RMS voltages for islanded operation before switching the capacitors. 
However, according to the Manitoba Hydro standards [18], the steady state voltage operating range for distribution systems above $1 \mathrm{kV}$ is $\pm 6 \%$ and the voltage unbalance is expected to be below $4 \%$ in the urban areas under normal operating conditions. Therefore, capacitor switching is important to meet the standards. Further, Figure 16 indicates that there is nearly $5 \%$ difference in the voltage levels observed between the microgrids with detailed and average models of DFIG before switching the capacitors, that is when the system is highly unbalance. This could happen due to the harmonic power losses in the microgrid modeled with the detailed DFIG design. Further research in this area is necessary to analyze and conclude on the findings. Also, the conventional DFIG control presented in this paper as the detailed model of DFIG is designed for balanced operating conditions, and weak performance of conventional control under unbalanced voltage conditions is discussed in many research proposing new control strategies for DFIG [19-21].

In this study, capacitors were switched depending on the measured phase voltages to meet the voltage limits specified in the standards. The switched capacitor bank was designed to balance and regulate the voltage to re-synchronize upon the availability of the utility grid [22].

Therefore, despite the possibility of switching of different levels of capacitors in the three phases according to the available voltage at the POI, the voltages of all three phases were properly regulated to meet the standards in the steady state. Accordingly, Figure 17 shows that with the switching of capacitors, the voltages observed at all the buses with both standard and average DFIG models match each other giving a maximum error of only $0.8 \%$ in Phase-a voltages.

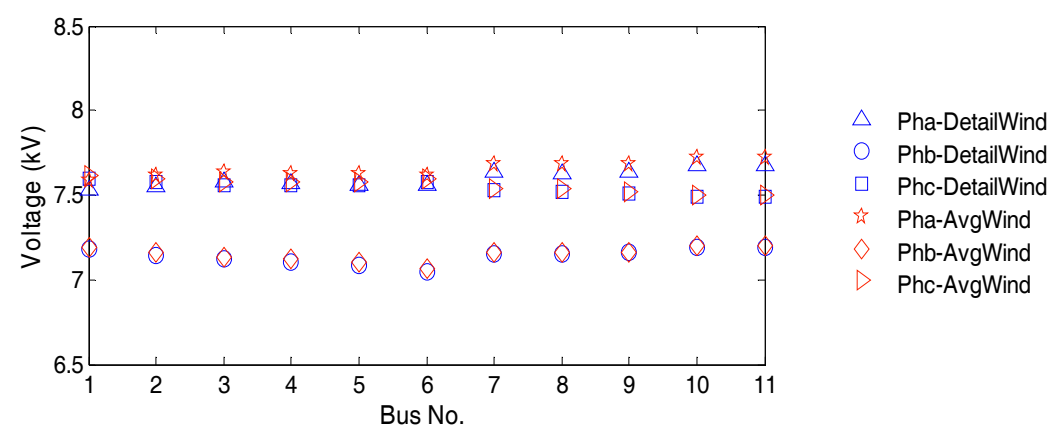

Figure 17. Comparison of DFIG models in steady state operating phase RMS voltages for islanded operation after switching the capacitors.

\subsection{Transient Operation of the Microgrid}

In analyzing the transient behaviour of the microgrid in grid connected operation, that is when the system is very strong being connected to an infinite bus, DFIG controls operated accurately and average model behaved very much closer to the detail model as observed with the simple radial test system.

It is interesting to observe the results when the wind turbine driven DFIG is operated in the islanded microgrid. In the islanded mode of operation, system frequency is controlled by a small synchronous generator. In the transition period, system undergoes a scheduled load shedding [15] and capacitor switching [22] to regulate the system frequency and voltages to standards [18]. In this context, while the wind turbine driven DFIG is being connected to a weak system, DFIG controls and designed average DFIG model need to control the active power and terminal voltage to the specified levels under several severe transient conditions when the microgrid is islanded.

Figure 18 illustrates the active and reactive power output variations of the sources, DFIG terminal voltage, DFIG speed and the DC voltage at the stator side control for using average and detailed model of the DFIG for a microgrid islanding. The corresponding DFIG control reference signals are shown in Figure 19 showing the control reference signals $I_{q}$ and $I_{d}$ at the rotor side, and $V_{d}$ and $V_{q}$ at the stator side for both average and standard detailed models of DFIG. 
Initially microgrid is connected to the grid and frequency is controlled by the grid while the synchronous generator being in the constant power, voltage regulation mode of operation. At $40 \mathrm{~s}$ the microgrid is islanded and synchronous generator control changes to isochronous operation. The wind turbine driven DFIG is expected to regulate its outputs to deliver a constant active power and reactive power in both grid connected and islanded operation. The microgrid islanding is followed by sequence of transient stages. After the microgrid is islanded, there is a scheduled static load shedding [15], happening at four stages to match the energy generation with demand in the islanded microgrid. After the frequency stabilized, capacitor switching occurs at the POI [22] to meet the required distribution system standards [18]. To further illustrate accurate operation of DFIG controllers and average model of DFIG, a three phase to ground fault is introduced at the DFIG terminal at $t=75 \mathrm{~s}$ and wind speed was given a step change from $11.5 \mathrm{~ms}^{-1}$ to $10.5 \mathrm{~ms}^{-1}$ at $t=95$ sand back to $11.5 \mathrm{~ms}^{-1}$ at $t=125 \mathrm{~s}$.

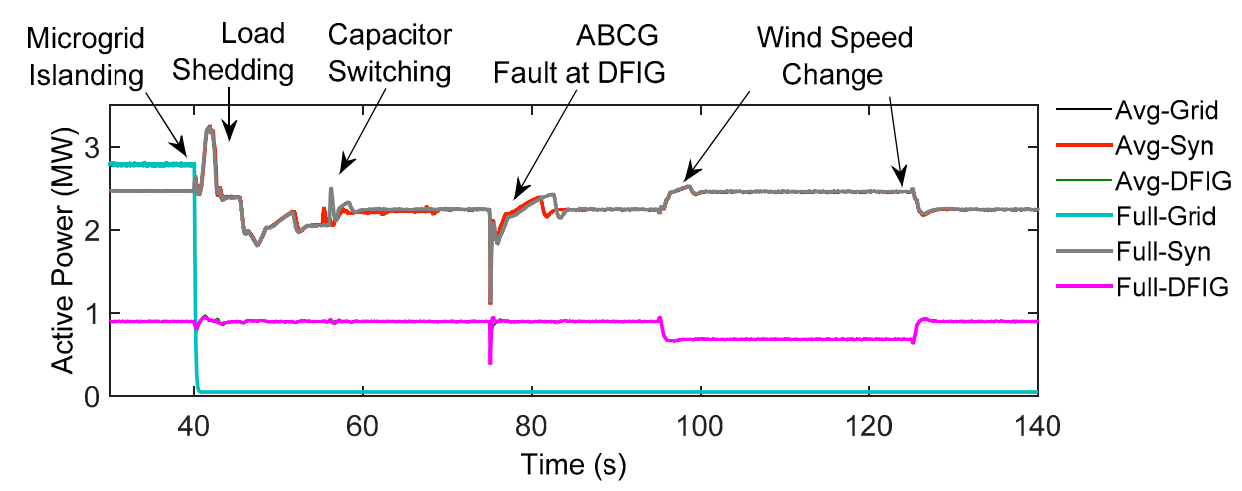

(a)

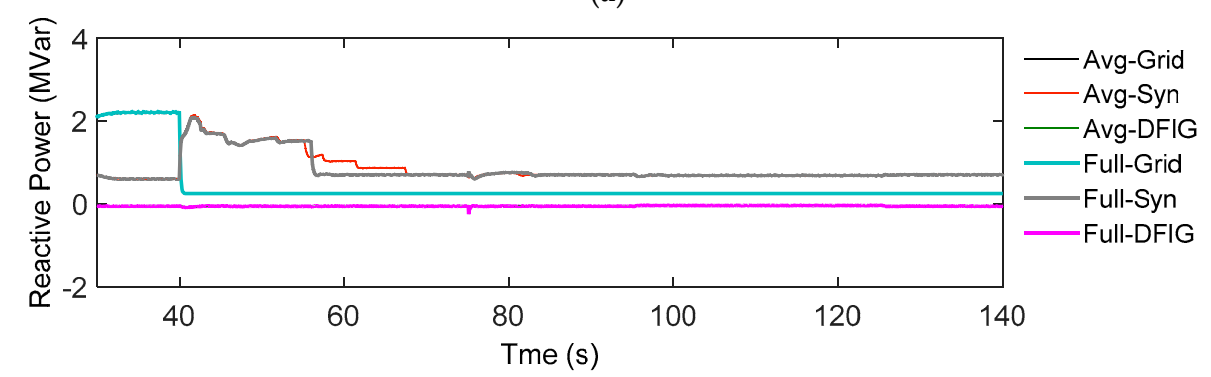

(b)

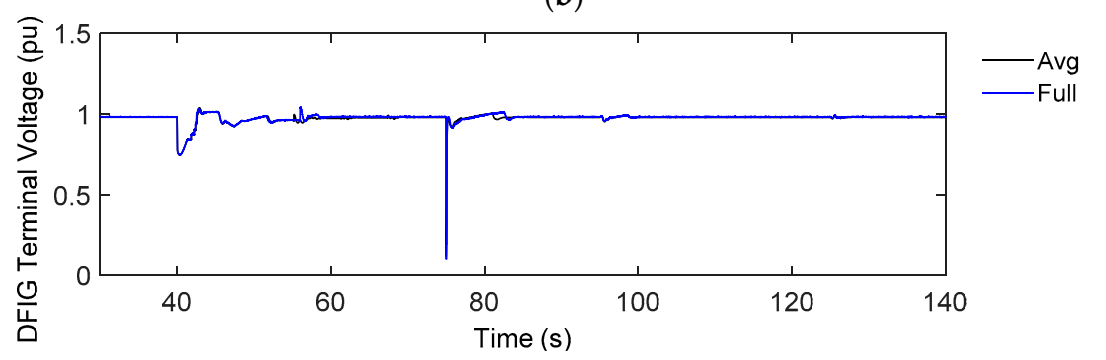

(c)

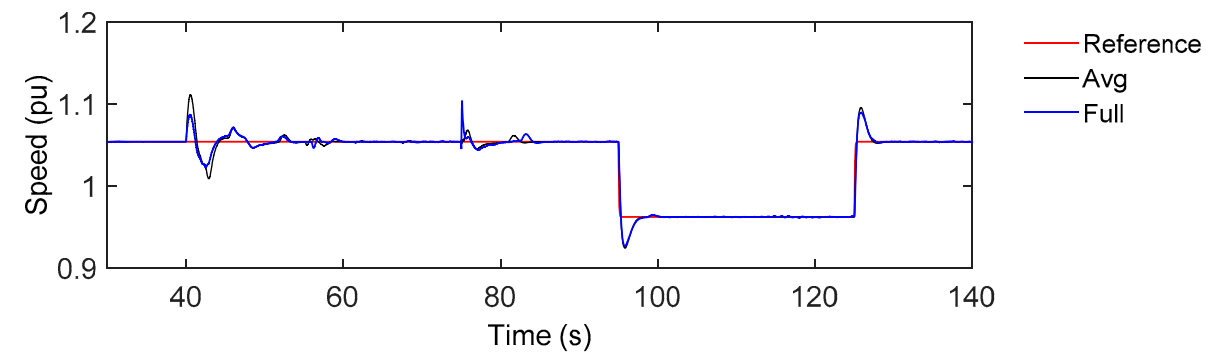

(d)

Figure 18. Cont. 


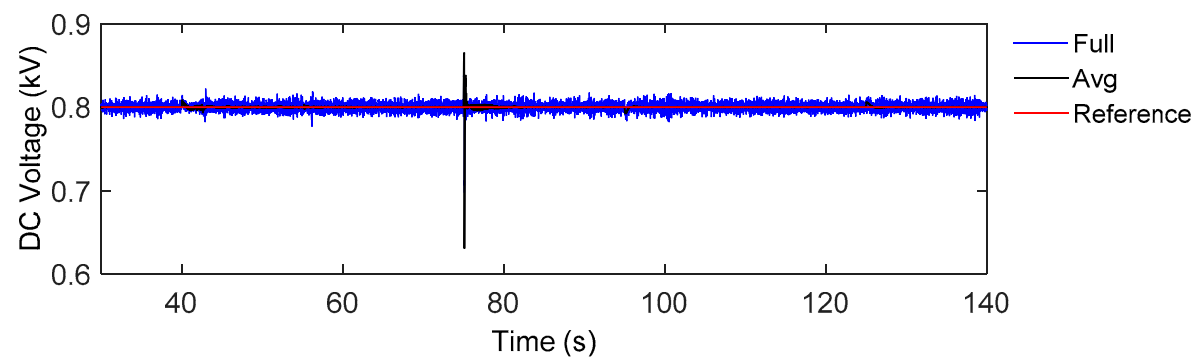

(e)

Figure 18. Outputs when the microgrid is islanded and followed by different transients: (a) active power outputs, (b) reactive power outputs, (c) load bus voltage, (d) DFIG speed, (e) DC voltage.

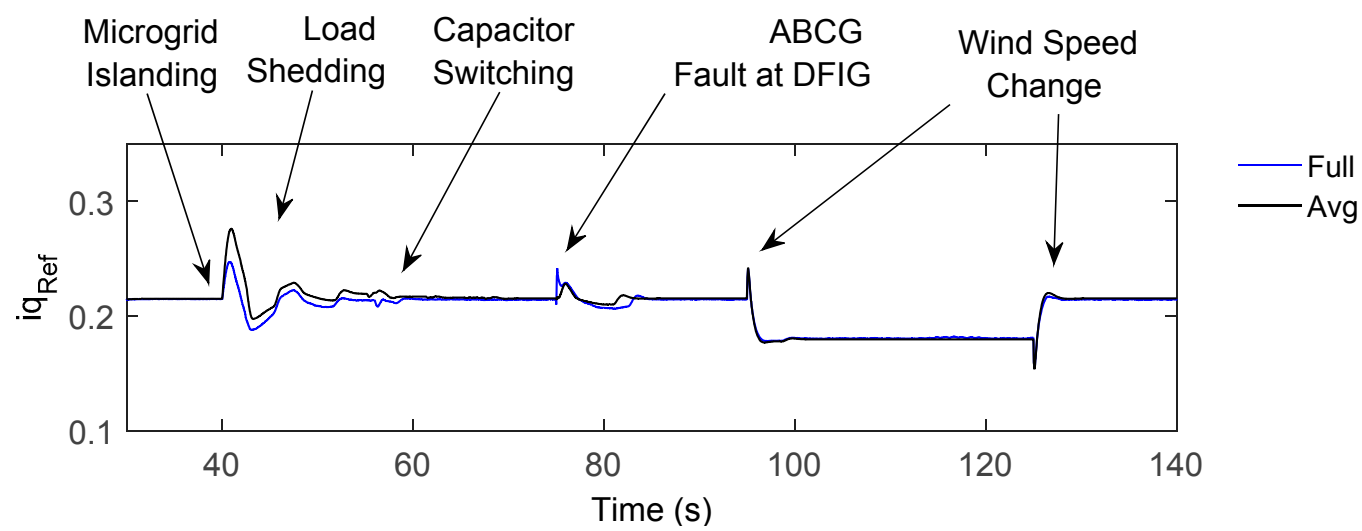

(a)

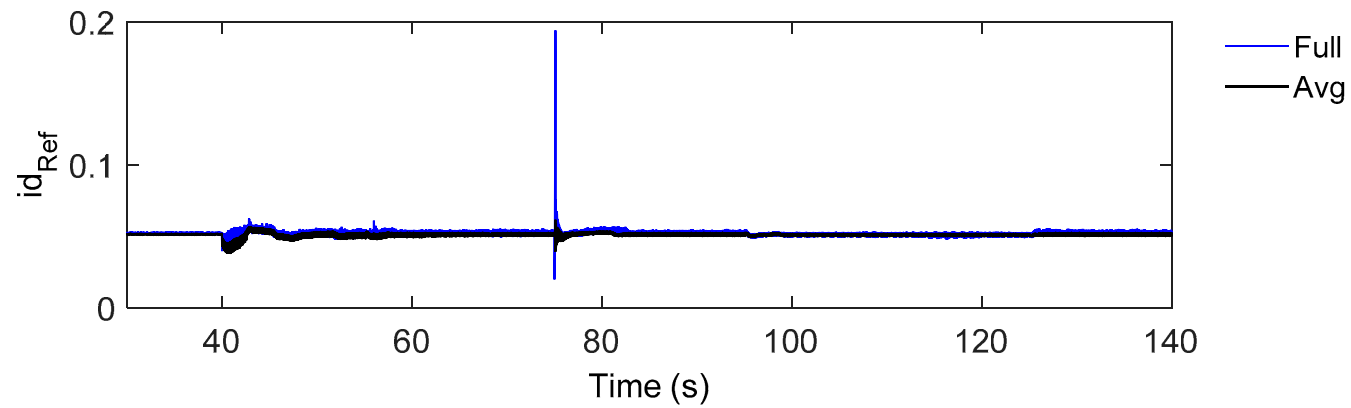

(b)

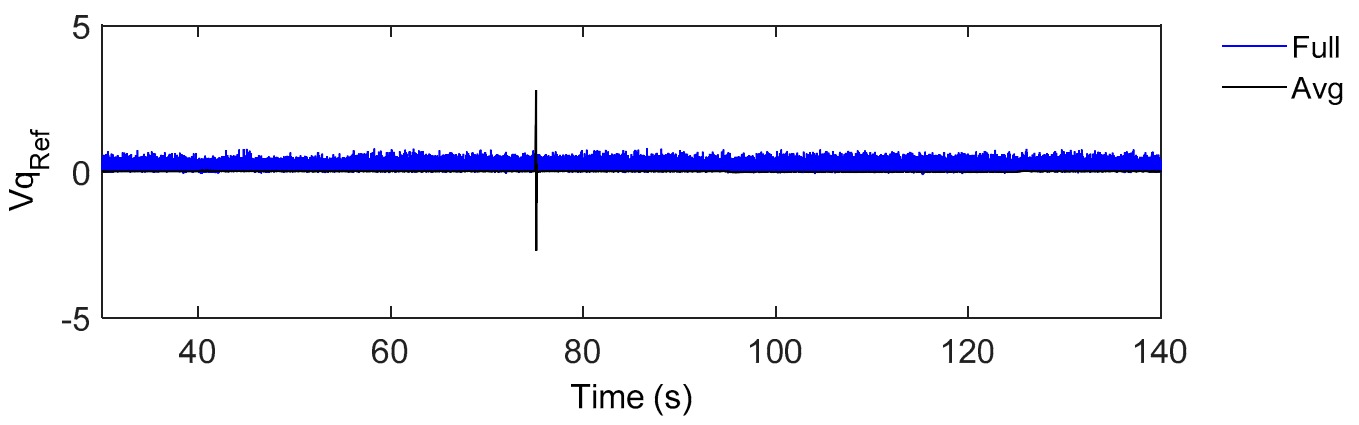

(c)

Figure 19. Cont. 


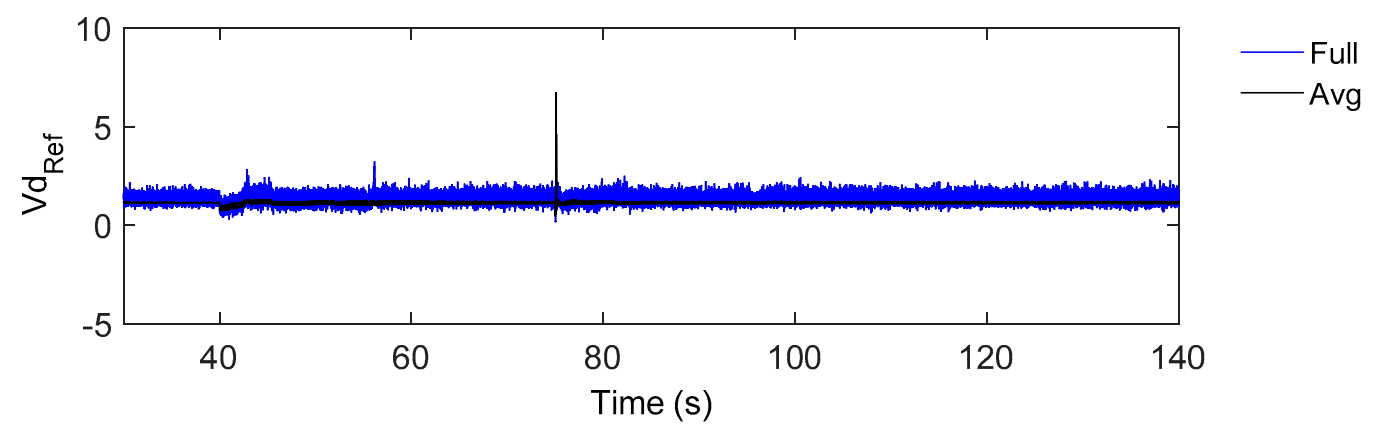

(d)

Figure 19. Control reference signals when microgrid is islanded and followed by different transients: (a) $I_{q},(\mathbf{b}) I_{d},(\mathbf{c}) V_{q},(\mathbf{d}) V_{d}$.

Figures 18 and 19 confirm the accuracy of the designed average DFIG model by giving highly comparable results under several severe power system transients. In this simulation IGBTs of the detailed model were connected without the snubber-circuits to investigate the effect of snubbers. Without the snubber-circuits being present, it introduces ripples on the DC voltage and higher switching transients in control signals. However, there is no significant improvement in the processing time compared to the detailed model including the snubber-circuits in IGBTs.

Simulations were carried using an Intel Core i5-5200 U CPU @ $2.2 \mathrm{GHz}$ processor. Comparing the processing times involved, while it takes $150 \mathrm{~s}(2.5 \mathrm{~min})$ real-time to simulate $1 \mathrm{~s}$ with the detailed model of DFIG, it takes only $30 \mathrm{~s}$ real-time to simulate $1 \mathrm{~s}$ using the average model of DFIG. The verified average model of DFIG can be used effectively in transient stability studies requiring long duration simulations.

\section{Conclusions}

The paper elaborated on modeling of a wind turbine driven DFIG using an electromagnetic transient simulation software. It discussed the modeling of the converters and their basic controls for the conventional detailed DFIG model having power electronic converters represented with switching devices. An average DFIG model, which represent the converters with controlled current and voltage sources was developed and validated against the detailed DFIG model using a small test system, and showed that the average model gives comparable results.

It was observed that simulating with the average DFIG model is five times faster than the detailed DFIG model. Having an accurate average model performing very fast, it can be effectively used in transient stability studies, and studying sub synchronous oscillations demanding long duration simulations or in studying wind farm dynamics in large power systems.

The effectiveness of the designed DFIG models was further illustrated through the application of models in a distribution level microgrid. Simulation examined the behaviour of the microgrid and DFIG controllers under different steady state and severe transient operating scenarios. It was observed that when the system is unbalanced, steady state RMS bus voltages observed with the designed average DFIG model slightly deviate from those observed with the detailed model. Further investigation is required in this area to conclude whether it is an effect of power losses due to harmonics in using the detailed model of DFIG in the system. An improved control algorithm designed for unbalanced systems would be a solution and it is being investigated. The representation of PWM using controlled sources is also been investigated as future work.

Author Contributions: Lidula Widanagama Arachchige, Athula Rajapakse and Dharshana Muthumuni conceived and designed the conventional and average DFIG model; Lidula Widanagama Arachchige performed the experiments and Lidula Widanagama Arachchige and Athula Rajapakse analyzed the results; Lidula Widanagama Arachchige wrote the paper with the feedback of Athula Rajapakse and Dharshana Muthumuni.

Conflicts of Interest: The authors declare no conflict of interest. 


\section{Appendix A}

(i) PSCAD model developed to find the instantaneous position of the resultant stator flux of DFIG

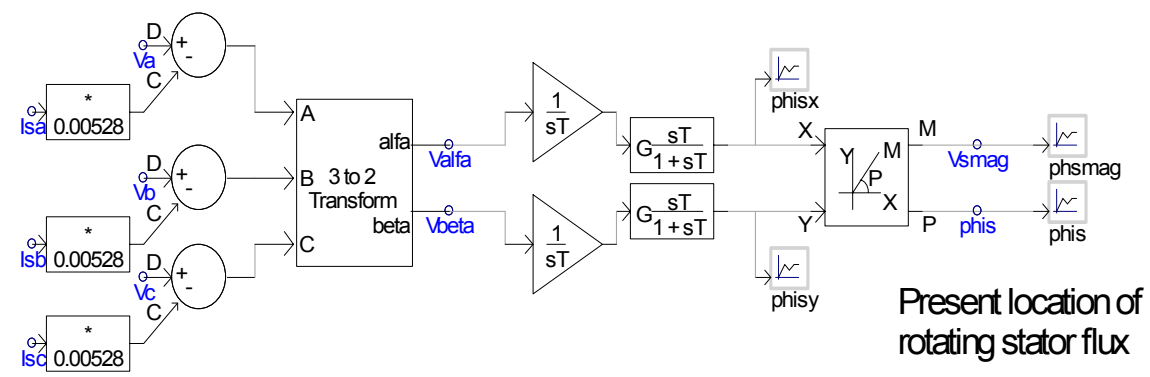

Figure A1. Finding the instantaneous position of the resultant stator flux of DFIG.

(ii) PSCAD model developed for rotor current control

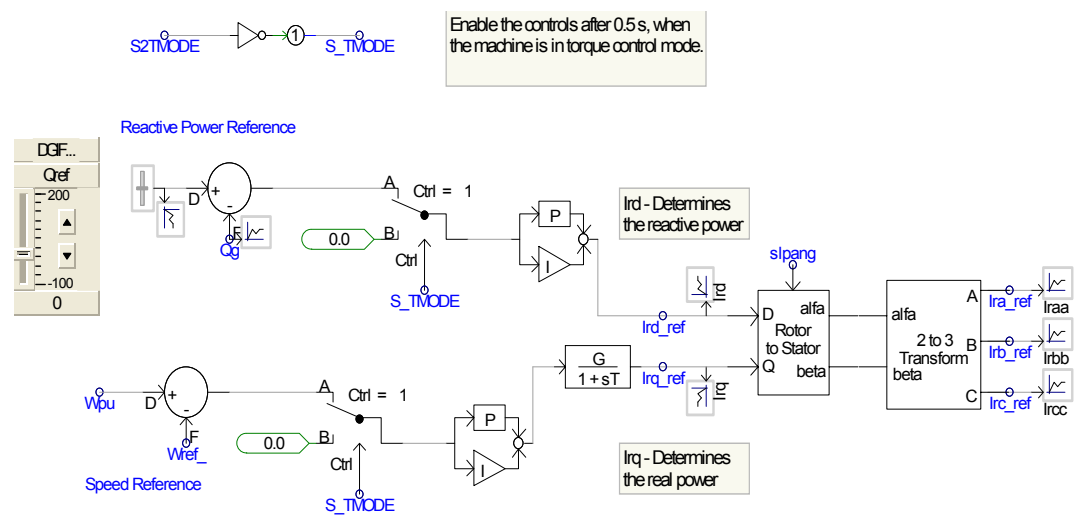

Figure A2. Rotor current control.

(iii) PSCAD model developed for hysteresis current control for firing IGBTs of rotor side converter

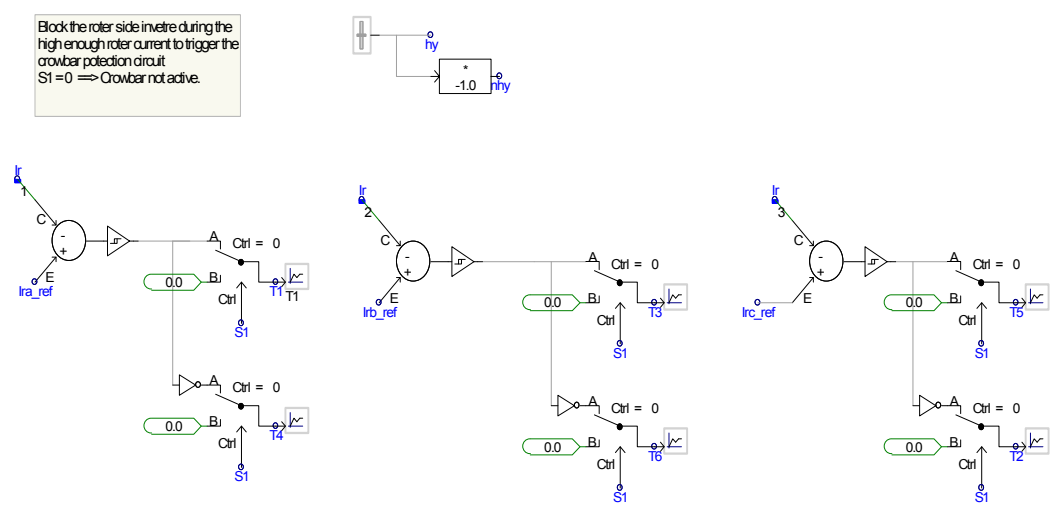

Figure A3. Hysteresis current control for firing IGBTs of rotor side converter.

(iv) PSCAD model developed for DC voltage control 


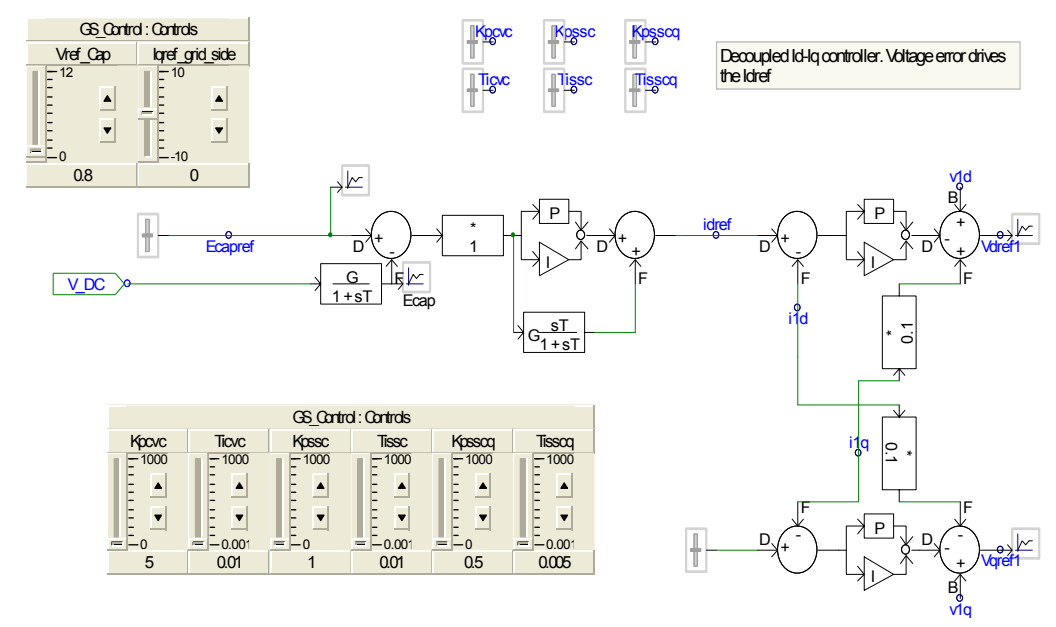

Figure A4. DC voltage control.

(v) PSCAD model developed for PWM control of the grid side converter

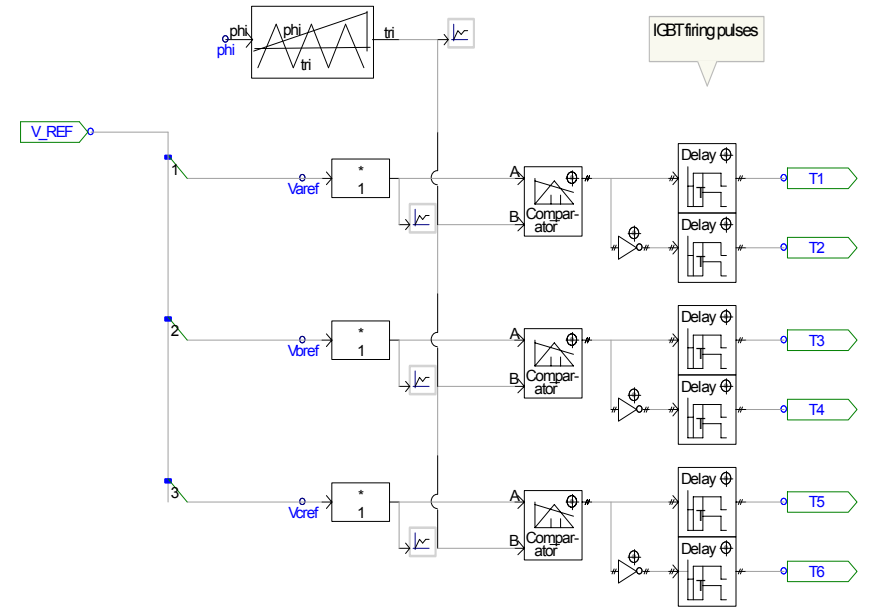

Figure A5. PWM control of the grid side converter.

\section{Appendix B}

(i) PSCAD model developed to replace the rotor side converter

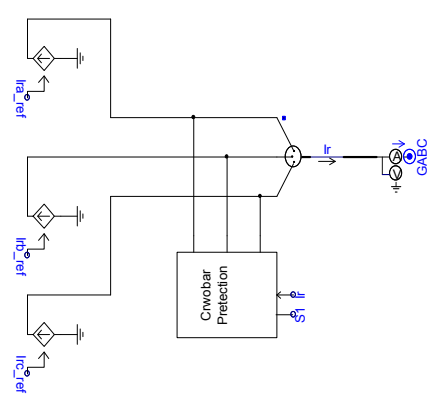

Figure A6. Rotor side of the average model of DFIG.

(ii) PSCAD model developed to replace the grid side converter 


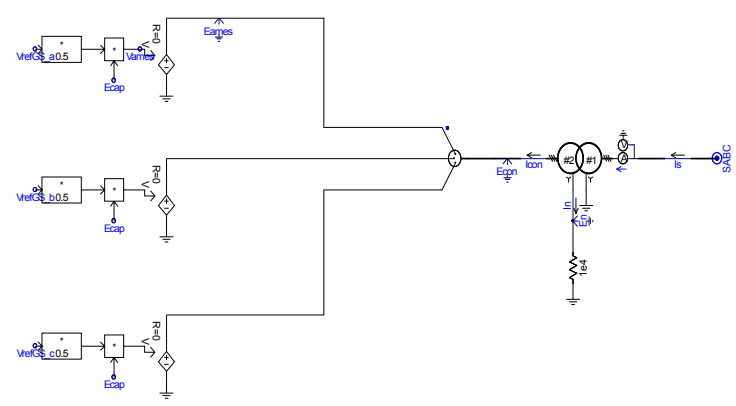

Figure A7. Grid side of the average model of DFIG.

(iii) PSCAD model to replace the grid side converter DC voltage controller

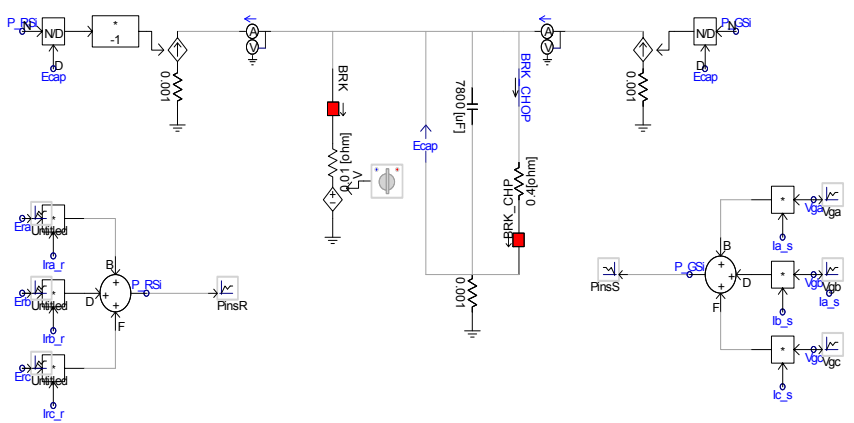

Figure A8. DC voltage controller of the average DFIG model.

\section{References}

1. CanWEA, the Canadian Wind Energy Association. Powering Canada's Future. 2016. Available online: https: / / canwea.ca/wp-content/uploads/2017/03/Canada-Current-Installed-Capacity_e.pdf (accessed on 1 October 2017).

2. Global Wind Energy Council, Global Wind Report, Annual Marker Update. 2016. Available online: http:/ / gwec.net/publications/global-wind-report-2/global-wind-report-2016/ (accessed on 1 October 2017).

3. Li, H.; Chen, Z. Overview of different wind generator systems and their comparisons. IET Renew. Power Gener. 2008, 2, 123-138. [CrossRef]

4. Zhao, J.; Lyu, X.; Fu, Y.; Hu, X.; Li, F. Coordinated microgrid frequency regulation based on DFIG variable coefficient using virtual inertia and primary frequency control. IEEE Trans. Energy Convers. 2016, 31, 833-845. [CrossRef]

5. Huang, P.; El Moursi, M.S.; Xiao, W.; Kirtley, J.L. Subsynchronous Resonance Mitigation for Series-Compensated DFIG-Based Wind Farm by Using Two-Degree-of-Freedom Control Strategy. IEEE Trans. Power Syst. 2015, 30, 1442-1454. [CrossRef]

6. Hosseini, S.H.; Sharifian, M.B.B.; Shahnia, F. Dynamic performance of double fed induction generator for wind turbines. In Proceedings of the Eighth International Conference on Electrical Machines and Systems (ICEMS 2005), Nanjing, China, 27-29 September 2005; Volume 2, pp. 1261-1266.

7. Ekanayake, J.B.; Holdsworth, L.; Wu, X.; Jenkins, N. Dynamic modeling of doubly fed induction generator wind turbines. IEEE Trans. Power Syst. 2003, 18, 803-809. [CrossRef]

8. Gagnon, R.; Sybille, G.; Bernard, S.; Paré, D.; Casoria, S.; Larose, C. Modeling and real-time simulation of a doubly-fed induction generator driven by a wind turbine. In Proceedings of the International Conference on Power Systems Transients (IPST'05), Montreal, QC, Canada, 19-23 June 2005.

9. Ying, J.; Yuan, X.; Hu, J. Inertia Characteristic of DFIG-based WT under Transient Control and Its Impact on the First-Swing Stability of SGs. IEEE Trans. Energy Convers. 2017. [CrossRef]

10. Wang, Y.; Xu, L.; Williams, B.W. Compensation of network voltage unbalance using doubly fed induction generator-based wind farms. IET Renew. Power Gener. 2009, 3, 12-22. [CrossRef] 
11. Xu, L.; Andersen, B.R.; Cartwright, P. VSC transmission operating under unbalanced AC conditions-Analysis and control design. IEEE Trans. Power Deliv. 2005, 20, 427-434. [CrossRef]

12. Zhao, C.; Guo, C. Complete-independent control strategy of active and reactive power for vsc based HVDC system. In Proceedings of the IEEE Power \& Energy Society General Meeting (PES '09), Calgary, AB, Canada, 26-30 July 2009; pp. 1-6.

13. Wu, B.; Lang, Y.; Zargari, N.; Kouro, S. Power Conversion and Control of Wind Energy Systems; The Institute of Electrical and Electronics Engineers; John Wiley \& Sons, Inc.: Hoboken, NJ, USA, 2011; pp. 322-323.

14. WWD-1, Appendix 10-Technical Specification 1, Ver 8-1/2003 Winwind Oy, Elektroniikkatie 2B, FIN-90570 OULU. Available online: http://www.ecosource-energy.bg/uploads/Technical_Specification_WWD1.pdf (accessed on 1 October 2017).

15. Lidula, N.W.A.; Rajapakse, A.D. Impact of Islanding Detection Time Duration on the Stable Operation of a Synchronous Generator Controlled Microgrid. Technol. Econ. Smart Grids Sustain. Energy 2017, 2. [CrossRef]

16. Strunz, K. Developing Benchmark Models for Studying the Integration of Distributed Energy Resources. In Proceedings of the 2006 IEEE Power Engineering Society General Meeting, Montreal, QC, Canada, 18-22 June 2006.

17. IEEE Working Group. Modelling and Analysis of System Transients Using Digital Programs; Velasco, J.M., Keri, A.J.F., Gole, A.M., Eds.; IEEE Operations Center: Piscataway, NJ, USA, 1999.

18. Hydro, M. Technical Requirements for Connecting Distributed Recourses to the Manitoba Hydro System; DRG 2003; Revision 2; Manitoba Hydro Electric Board: Winnipeg, MB, Canada, 2010.

19. Rezaei, E.; Ebrahimi, M.; Tabesh, A. Control of DFIG Wind Power Generators in Unbalanced Microgrids Based on Instantaneous Power Theory. IEEE Trans. Smart Grid 2017, 8, 2278-2286. [CrossRef]

20. Javan, E.; Darabi, A. A New Control Strategy of DFIG-Based Wind Turbines under Unbalanced Grid Voltage Conditions. In Proceedings of the 2nd Power Electronics, Drive Systems and Technologies Conference, Tehran, Iran, 16-17 February 2011.

21. Zeeshan, A.; Sinha, S.K. Control of DFIG under unbalanced grid voltage conditions: A literature review. In Proceedings of the 2016 International Conference on Control, Computing, Communication and Materials (ICCCCM), Allahabad, India, 21-22 October 2016.

22. Lidula, N.W.A.; Rajapakse, A.D. Voltage Balancing \& Synchronization of Microgrids. Renew. Sustain. Energy Rev. J. 2014, 31, 907-920. 